\title{
Hydrophobe-free miniemulsion polymerization: towards high solid content of fatty acid-based poly(urethane-urea)s latexes
}

\author{
E. Rix, ${ }^{a b}$ G. Ceglia, ${ }^{a b}$ J. Bajt, ${ }^{a b}$ G. Chollet, ${ }^{c}$ V. Heroguez, ${ }^{a b}$ E. Grau ${ }^{a b}$ and H. \\ Cramail*ab
}

Polyurethane-urea latex particles were synthesized by miniemulsion polyaddition of fatty acid-based diol derivatives and isophorone diisocyanate. The influence of the solid content, the surfactant and the hydrophobic agent was studied. Stable monodispersed latex particles with diameters around 200-300nm were obtained with solid content up to $50 \mathrm{wt} \%$, without use of any additional hydrophobic agent.

Due to the depletion of fossil carbon resources, biomass as a sustainable resource is gaining importance. Among them, vegetable oils are interesting molecules for polymer synthesis through the derivatization of their functional groups. ${ }^{1-6}$ They are easily turned into diols or polyols that can be used for the synthesis of polyurethanes $(\mathrm{PU}){ }^{7-12}$ Moreover, the literature also describes few examples of vegetable-based diisocyanates. ${ }^{13-15}$

Polyurethanes are commodity polymers that are used in a wide range of applications, from foams to textile fibers or glues. Polyurethane latexes are interesting for coating and adhesive applications. Most aqueous PU dispersions are made via the commonly called "acetone process". ${ }^{16}$ The principle is to polymerize in a volatile organic solvent, usually acetone, and to subsequently disperse the polymer mixture in water and then to evaporate the organic solvent. This enables the production of non-VOC aqueous PU dispersions. Recent works use vegetable-based polyols ${ }^{17,18}$ from triglycerides and also vegetable-based diisocyanates ${ }^{19,20}$ to get fully biobased PU. Still, this method uses organic solvents.

A greener route to non-VOC aqueous PU dispersions can be through miniemulsion polymerization. It was initially designed for radical polymerizations but the polymerization mechanisms have been extended over the years. In 2000, Landfester et al. were the first to describe polyadditions by miniemulsion polymerization with bis-epoxides and diamines. ${ }^{21}$ They further described the miniemulsion polyaddition of isophorone diisocyanate (IPDI) and 1,12-dodecanediol using hexadecane as a hydrophobic agent. ${ }^{22}$ The polyurethane latexes obtained with solid contents around 20wt\% exhibit particle sizes around $200 \mathrm{~nm}$. More recently, Chiu et al. produced high molecular weight $\mathrm{PU}$ by miniemulsion polymerization of IPDI and poly(tretramethylene oxide). ${ }^{23}$ The authors obtained large particles around 800-900nm with molecular weights up to $26 \mathrm{~kg} / \mathrm{mol}$ but did not report the solid content. Other works introduced natural triols as polyols, such as castor oil. Cramail and coll. reported aqueous PU latexes with $5 \mathrm{wt} \%$ solid content and particle sizes of $200-300 \mathrm{~nm}^{24}$. Sayer and coll. also obtained latexes with $20 \mathrm{wt} \%$ of solid content with particle sizes of $180 \mathrm{~nm}$ and PU molar mass around $5800 \mathrm{~g} / \mathrm{mol}$ with a dispersity of $1.55 .{ }^{25}$

In all these examples of PU synthesis through miniemulsion process, the authors pointed out the formation of urea linkages. This is due to the side reaction between water and isocyanate to form amine units that subsequently react with isocyanate to form urea functions. According to Landfester, this side reaction is slower than the reaction of IPDI with alcohol thus limiting the urea content in the final polymer. ${ }^{22}$

Furthermore, during the miniemulsion polymerization, a hydrophobic agent is needed to prevent Ostwald ripening. This agent may modify the resulting polymer and the coating features. Hexadecane is the most widely used hydrophobic agent but vegetable oils such as olive oil and açaí oil have been tested as hydrophobic agents to prepare polyurethane latexes. ${ }^{24-26}$

To remain on the "green" track, such additives have to be removed. There are scarce examples in the literature of hydrophobe-free miniemulsion polymerization. ${ }^{27-29}$ In all cases, the surfactant is the sole stabilizer and plays also the role of hydrophobe: for Charleux and coll. and Landfester and coll., the surfactant is a comb-like charged copolymer while for Liu and coll., it is a Y-like branched castor oil derivative. More recently, Singha and coll. performed RAFT polymerization of a fluorinated acrylate in miniemulsion. The RAFT agent used contains a long alkyl chain with 12 carbons. The high hydrophobicity of the monomer and the RAFT agent allowed miniemulsion polymerization with SDS or Triton X-450 as surfactant. ${ }^{30}$

In this study, a hydrophobe-free formulation was developed to get semi-biobased aqueous PU latexes. Sodium dodecyl sulphate (SDS) was used as a surfactant. Two bio-based diols from ricinoleic acid were easily synthesized. The polymerizations were performed in bulk and miniemulsion with solid contents up to $50 \mathrm{wt} \%$. 


\section{Materials and Method}

The biobased diols used in this study are the butanediol monoester RicBmE and the propanediol monoester RicPmE obtained from ricinoleic acid (Fig.1). The synthesis of such diols has already been described by Cramail et al. ${ }^{31}$ Isophorone diisocyanate IPDI is used as the comonomer and dibutyltin dilaurate (DBTDL) as the catalyst, the latter being used at the concentration of $0.4 \mathrm{wt} \%$ of the organic phase.

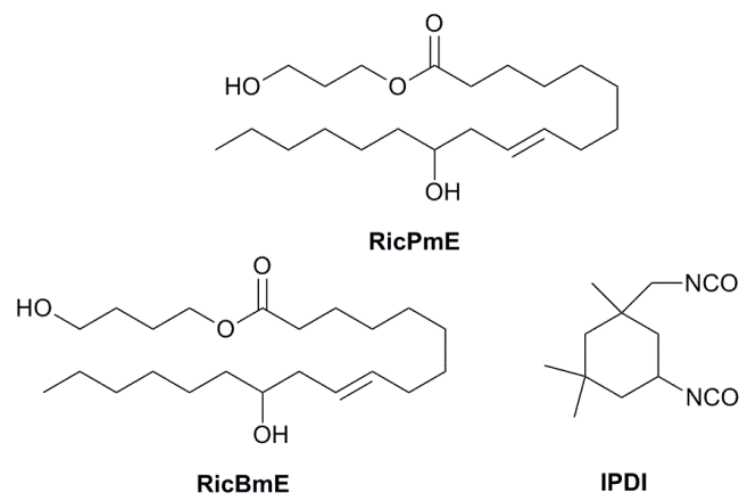

Fig. 1: Castor oil diol derivatives RicBmE, RicPmE and isophorone diisocyanate IPDI.

The organic phase is composed of the monomers, the catalyst and the hydrophobic agent while the aqueous phase consists of deionized water and a surfactant (sodium dodecyl sulphate).

The miniemulsions are obtained by ultrasonicating the system for $120 \mathrm{sec}$ in an ice bath (Bioblock Scientific Vibracell ${ }^{\mathrm{TM}}, 750 \mathrm{~W}, 40 \%$ amplitude). Then the polymerization is carried out at $60^{\circ} \mathrm{C}$ for $4 \mathrm{~h}$ with mechanical stirring at $300 \mathrm{rpm}$. Particle sizes were measured by dynamic light scattering (DLS) with a Zetasizer Nano ZS from Malvern. Samples were diluted in continuous phase before analysis.

\section{Results and Discussion}

RicBmE and RicPmE are easily synthesized in a single step by trans-esterification of ricin oil with 1,4-butanediol or 1,3propanediol and then polymerized with IPDI catalysed by DBTDL to yield polyurethane. Bulk polymerization of RicPmE and IPDI at $60^{\circ} \mathrm{C}$ leads to an amorphous polymer with a glass transition temperature of $14^{\circ} \mathrm{C}$, and $\mathrm{Mn}$ of $30000 \mathrm{~g} / \mathrm{mol}(Đ \approx 3.3)$. Similar results are obtained with $\mathbf{R i c B m E}$.

The system was transposed to miniemulsion. In order to obtain the highest solid content and monomer conversion, parameters such as the solid content, the hydrophobic agent and the number of IPDI equivalent were studied. Finally, the side reaction of isocyanate with water giving urea units was investigated.

\section{Influence of the hydrophobic agent}

Two hydrophobic agents were studied: hexadecane and stand oil. The first one is a largely used hydrophobic agent and the second one is a linseed oil derivative. For $20 \mathrm{wt} \%$ of solid content, miniemulsions were obtained with similar characteristics whatever the hydrophobic agent. The droplet size of the miniemulsion and the particle size of the latex were similar, around $200 \mathrm{~nm}$. The same experiment was performed without hydrophobic agent and similar results were obtained. Results are summarized in Table 1.

Surprisingly, no hydrophobic agent was needed to improve the stability of the droplets and the latex particles. This phenomenon is explained by the high hydrophobicity of RicBmE molecule ${ }^{32,} \boldsymbol{T}$ which plays the hydrophobe role and thus prevents the Ostwald ripening.

Table 1: Influence of the solid content and the hydrophobic agent on the particle size.

\begin{tabular}{cccc}
\hline $\begin{array}{c}\text { Solid content } \\
(w t \%)\end{array}$ & $\begin{array}{c}\text { Hydrophobic agent }(3.2 w t \% \\
\text { of the organic phase })\end{array}$ & $\begin{array}{c}\text { [SDS] } \\
(\mathrm{CMC})^{a}\end{array}$ & $\begin{array}{c}\text { Particle size } \\
(\mathrm{nm})[\mathbf{P D I}]^{b}\end{array}$ \\
\hline 20 & Hexadecane & 3.5 & $220[0.206]$ \\
20 & Stand oil & 3.5 & $210[0.139]$ \\
20 & No hydrophobe & 3.5 & $230[0.180]$ \\
\hline 30 & No hydrophobe & 3.5 & $200[0.118]$ \\
\hline 40 & No hydrophobe & $5.2^{c}$ & $245[0.176]$ \\
\hline 50 & No hydrophobe & $5.2^{c}$ & $270[0.183]$ \\
\hline
\end{tabular}

RicBmE and IPDI were used in stoichiometric proportions. DBTDL concentration was $0.4 \mathrm{wt} \%$ of the organic phase. ${ }^{a} 1 \mathrm{CMC}=2.34 \mathrm{mg} / \mathrm{mL}-$ critical micellar concentration of SDS. ${ }^{b}$ Measured by DLS with a $90^{\circ}$ angle. ${ }^{c}$ Lower amounts of SDS gave unstable miniemulsions.

The solid content can be increased up to 50wt $\%$. Nevertheless, the concentration of SDS in the continuous phase has to be slightly increased for 40 and $50 \mathrm{wt} \%$ solid content systems to obtain stable systems. When increasing the solid content, the number of particles raises and thus the surface of the interface too. Then, more surfactant is needed to cover the entire surface. Moreover, the particle size increases slightly with the solid content, up to $270 \mathrm{~nm}$ at $50 \mathrm{wt} \%$.

Very interestingly, stable polyurethane latexes could be obtained with solid content up to $50 \mathrm{wt} \%$ in hydrophobe-free condition.

FTIR analysis of such latexes revealed the presence of urea units in the polymer backbone (see ESI S6). Urea formation during polyurethane synthesis is a known side reaction. ${ }^{22}$ As the reaction of isocyanates and water leads to the production of amines, and the subsequent reaction of amines with isocyanates to urea, the isocyanate ( $\mathrm{NCO}$ ) concentration is dropping along with the polymerization. Therefore, hydroxyls $(\mathrm{OH})$ are not fully converted at the end of the polymerization.

$\mathrm{Hu}$ et al. developed a method to calculate the amount of urea and urethane in waterborne PU using ${ }^{1} \mathrm{H}$ NMR in deuterated DMSO. ${ }^{33}$ Protons linked to the nitrogen atom have different chemical shifts in urea and urethane (see Fig.2.) enabling to calculate the urea content in the polymers by integration of the corresponding peaks. This method was used to determine the urea content in our systems using RicPmE as a diol (see ESI S4, S5). The results are summarized in Table 2. 


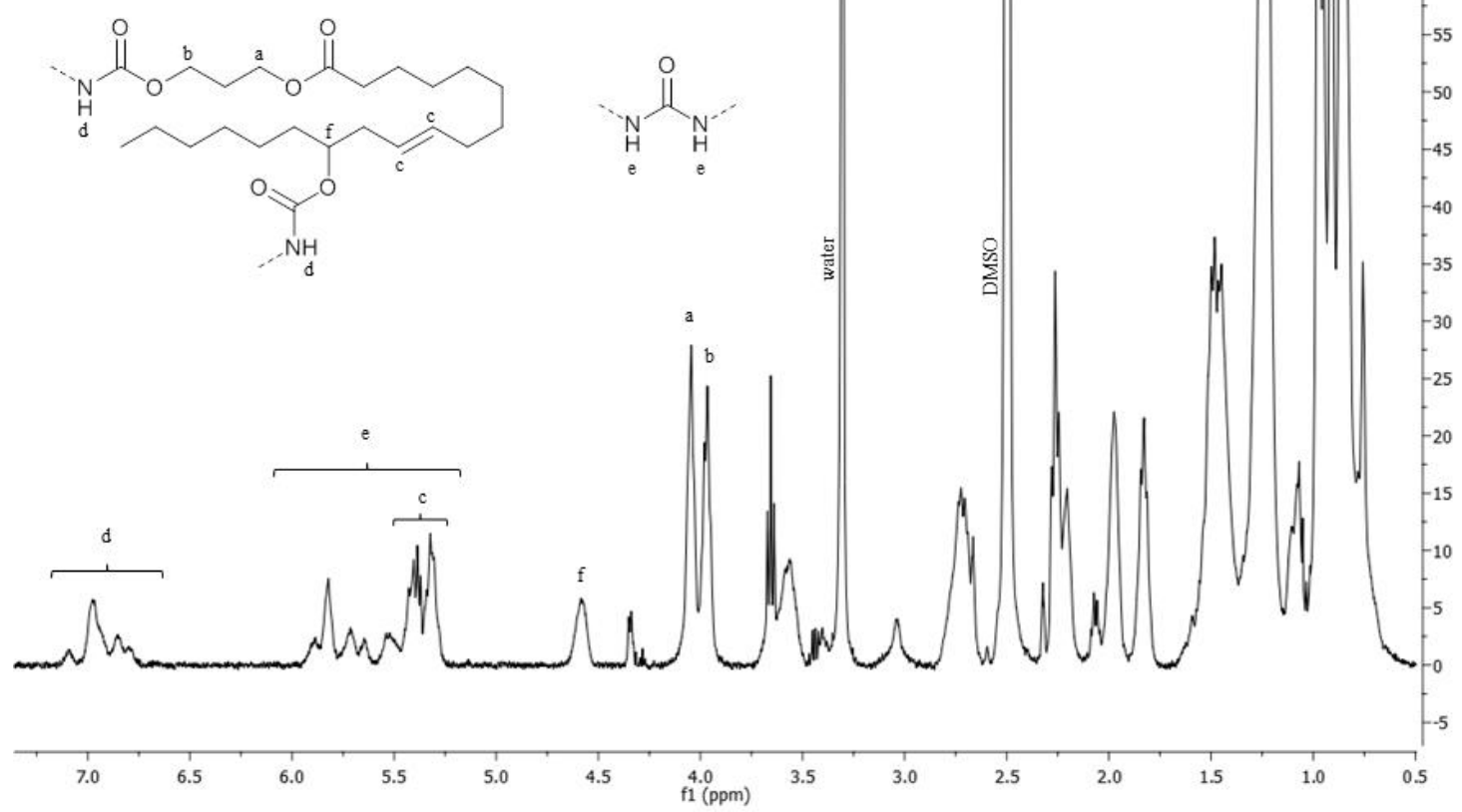

Fig.2: ${ }^{1} \mathrm{H}$ NMR in deuterated DMSO of lyophilized polymer latex with partial assignment. (RicPmE and IPDI were used as monomers, with 3.5 CMC of SDS. No hydrophobic agent was added. DBTDL concentration was $0.4 \mathrm{wt} \%$ of the organic phase.)

\begin{tabular}{cccc}
\hline Table 2: Influence of the hydrophobic agent on the urea content \\
\hline \multicolumn{4}{c}{} \\
\hline $\begin{array}{c}\text { Solid } \\
\text { content } \\
(w t \%)\end{array}$ & $\begin{array}{c}\text { Hydrophobic agent }(3.2 w t \% \\
\text { of the organic phase })\end{array}$ & $\begin{array}{c}\text { Particle size } \\
(\mathrm{nm})^{a}\end{array}$ & $\begin{array}{c}\text { Urea } \\
\text { content }^{b} \\
(\%)\end{array}$ \\
\hline 20 & Hexadecane & $240 \pm 8$ & 24 \\
20 & Sunflower oil & $250 \pm 14$ & 32 \\
20 & No hydrophobe & $238 \pm 19$ & 24 \\
\hline
\end{tabular}

RicPmE and IPDI were used in stoichiometric proportions, with 3.5 CMC of SDS. DBTDL concentration was $0.4 \mathrm{wt} \%$ of the organic phase.

${ }^{a}$ Measured by DLS with a $90^{\circ}$ angle. The value given is the average value of three measurements. Polydispersity indexes are between 0.143 and 0.232. ${ }^{b}$ Measured from ${ }^{1} \mathrm{H}$ NMR in DMSO on lyophilized latex.

The results obtained without hydrophobe and with hexadecane are similar with a urea content of $24 \%$. It means that the addition of a hydrophobic agent has no effect on this side reaction. This feature confirms the hypothesis that such side reaction occurs only at the interface of the droplets and that water is not diffusing in the organic phase. Furthermore, the urea content with sunflower oil as hydrophobic agent is higher. Sunflower oil mainly consists of triglycerides (95-99\%), but also contains other components such as unsaponifiable derivatives, which could explain the higher urea content.

\section{Influence of the $\mathrm{NCO/OH}$ ratio on hydrophobe-free miniemulsion polymerizations}

Studies on the influence of the $\mathrm{NCO} / \mathrm{OH}$ ratio were performed on the system at $20 \mathrm{wt} \%$ of solid content, with 3.5 CMC of SDS, using RicPmE as diol, without hydrophobic agent. The latexes obtained were lyophilized in order to analyse the crude polymers. The same reactions were performed in bulk to compare the polymer characteristics.

Table 3 summarizes the molar mass of the polymers obtained with different $\mathrm{NCO} / \mathrm{OH}$ ratio both in miniemulsion and bulk polymerization in brackets. In bulk, the molar masses follow the Carothers law: they logically drastically decrease when $\mathrm{NCO} / \mathrm{OH}$ is far from the stoichiometry. Obviously, the glass transition temperature follows the same trend.

\begin{tabular}{cccccc} 
Table 3: Characteristics of PU latex and [bulk PU] \\
\hline $\begin{array}{c}\text { NCO/OH } \\
\text { ratio }\end{array}$ & $\begin{array}{c}\mathbf{M w}^{\mathrm{a}, \mathrm{d}} \\
(\mathrm{kg} / \mathrm{mol})\end{array}$ & $\mathbf{D}^{\mathrm{a}, \mathrm{d}}$ & $\begin{array}{c}\text { Particle } \\
\mathbf{s i z e}^{\mathrm{b}} \\
(\mathrm{nm})\end{array}$ & $\begin{array}{c}\mathbf{T g}^{\mathrm{c}, \mathrm{d}} \\
\left({ }^{\circ} \mathrm{C}\right)\end{array}$ & $\begin{array}{c}\text { Urea } \\
\text { content }^{\mathrm{d}} \\
(\%)\end{array}$ \\
\hline $\mathbf{0 . 8}$ & $3.2[9.6]$ & $1.3[1.1]$ & $249 \pm 11$ & $-16[-12]$ & $21[5]$ \\
$\mathbf{1}$ & $3.7[38.2]$ & $1.4[3.5]$ & $238 \pm 19$ & $-5[14]$ & $24[-]^{\mathrm{d}}$ \\
$\mathbf{1 . 2}$ & $4.8[24.5]$ & $1.5[2.3]$ & $243 \pm 7$ & $9[12]$ & $30[-]^{\mathrm{d}}$ \\
$\mathbf{1 . 5}$ & $5.8[9.6]$ & $1.6[1.7]$ & $226 \pm 14$ & $32[-9]$ & $34[18]$ \\
$\mathbf{1 . 8}$ & $5.2[2]$ & $1.5[1.4]$ & $239 \pm 18$ & $69[-22]$ & $43[22]$ \\
$\mathbf{2}$ & $4.7[2]$ & $1.5[1.4]$ & $228 \pm 16$ & $69[-29]$ & $55[25]$ \\
$\mathbf{2 . 5}$ & 4.2 & 1.4 & $232 \pm 14$ & $n d$ & 55 \\
$\mathbf{3}$ & $n d$ & $n d$ & $220 \pm 6$ & $n d$ & 55
\end{tabular}

RicPmE and IPDI were used as monomers, with 3.5 CMC of SDS. No hydrophobic agent was added. DBTDL concentration was $0.4 \mathrm{wt} \%$ of the organic phase. ${ }^{a}$ Measured by SEC in THF calibrated with polystyrene standards. ${ }^{\mathrm{b}}$ Measured by DLS with a $90^{\circ}$ angle. The value given is the average value of three measurements. Polydispersity indexes are between 0.162 and 0.234 . ${ }^{\mathrm{c}}$ Measured by differential scanning calorimetry. ${ }^{\mathrm{d}}$ Polymers insoluble in deuterated DMSO. $n d$ : not determined

Following the mini-emulsion process, the molar masses are lower in comparison to the ones obtained in bulk polymerization and remain practically constant with the $\mathrm{NCO} / \mathrm{OH}$ ratio. Moreover the particle size is not affected and remains around $240 \mathrm{~nm}$. Indeed, the stoichiometry between the diol and the diisocyanate is difficult to achieve because of the side reaction between isocyanate and water, proved by the presence of unreacted alcohol in the final material. The conversion of each alcohol function (primary and secondary) can be calculated from ${ }^{1} \mathrm{H}$ NMR spectra in $\mathrm{CDCl}_{3}$ by integration of the peaks corresponding to the protons in alpha of the hydroxyl 
functions (see ESI S7). These hydroxyl functions are those of some RicPmE left and of the resulting polymer chain-ends. Results are shown in Fig.3 for both miniemulsion and bulk polymerisation.

For bulk polymers, as expected, the conversion is complete for both hydroxyl functions when there is enough diisocyanate to reach equivalence.

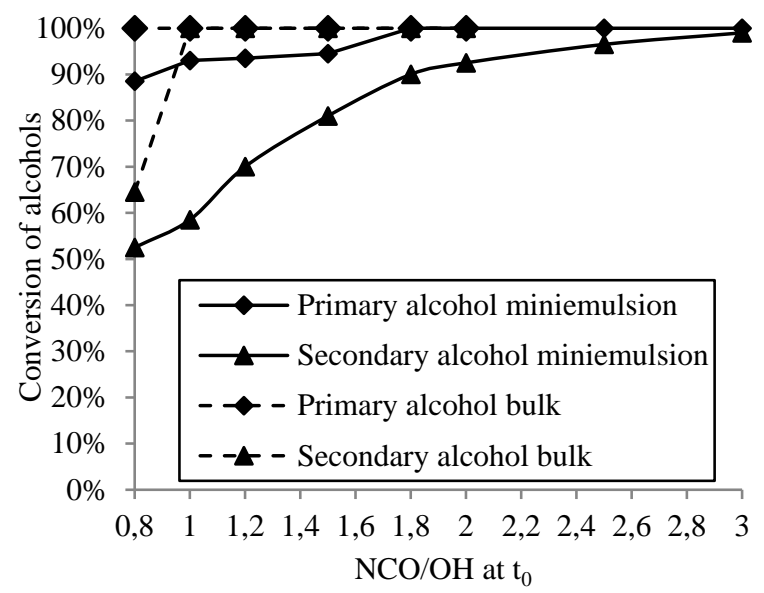

Fig.3: Conversion of primary and secondary alcohols according to ${ }^{1} \mathrm{H}$ NMR in $\mathrm{CDCl}_{3}$. (RicPmE and IPDI were used as monomers, with 3.5 CMC of SDS. No hydrophobic agent was added. DBTDL concentration was $0.4 \mathrm{wt} \%$ of the organic phase.)

For miniemulsion polymers, around the stoichiometric ratio, some unreacted RicPmE is left due to the formation of urea. For a $\mathrm{NCO} / \mathrm{OH}$ ratio of 1.5 , there is no more unreacted $\mathbf{R i c P m E}$ but still a lot of secondary $\mathrm{OH}$ chain-ends. Thus, by increasing the $\mathrm{NCO} / \mathrm{OH}$ ratio, one can increase the alcohol conversion without changing the latex particle size and stability. Indeed, full conversion can be achieved with a $\mathrm{NCO} / \mathrm{OH}$ ratio of 3 . In the meantime, the urea content increases thus affecting the polymer properties (Fig.4).

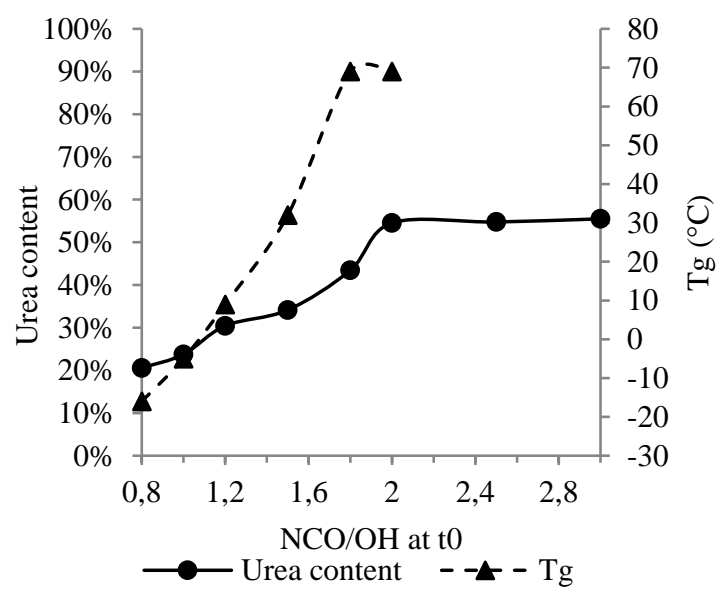

Fig.4: Evolution of the polymer characteristics with the $\mathrm{NCO} / \mathrm{OH}$ ratio at $t_{0}$ for the miniemulsion systems with $3.5 \mathrm{CMC}$ of SDS at $20 \mathrm{wt} \%$ of solid content. (RicPmE and IPDI were used as monomers, with 3.5 CMC of SDS. No hydrophobic agent was added. DBTDL concentration was $0.4 \mathrm{wt} \%$ of the organic phase.)

The conversion and the urea formation increase with the $\mathrm{NCO} / \mathrm{OH}$ ratio, from a urea content of $24 \%$ to $55 \%$ when $\mathrm{NCO} / \mathrm{OH} \geq 2$. These poly(urethane-urea)s have different thermomechanical properties compared to polyurethane. Urea functions harden the polymer, as proved by the higher Tg obtained with the urea content (Table 3 ). These transition temperatures can be compared to the $\mathrm{Tg}$ of the bulk polyurethane obtained with $\mathrm{NCO} / \mathrm{OH}=1$ which has a $\mathrm{Tg}$ of only $12^{\circ} \mathrm{C}$ (with a negligible quantity of urea). For $\mathrm{NCO} / \mathrm{OH}$ ratios of 0.8 to 1.2 , the $\mathrm{Tg}$ is below $12^{\circ} \mathrm{C}$, explained by the presence of unreacted RicPmE (Fig.3) that plasticises the polymer and thus decreases the Tg.

Finally, full diol conversion can be reached by playing with the $\mathrm{NCO} / \mathrm{OH}$ ratio, and the polyurethane-urea thermomechanical properties can be modulated.

\section{Conclusions}

High solid content bio-based poly(urethane-urea) latexes were obtained through miniemulsion polymerization. No hydrophobic agent was needed. The hydrophobic vegetable-based diol itself allows stabilizing the droplets against Ostwald ripening. Thus, the use of solvents or additives is avoided during the whole polymerization process. Lower molar masses compared to the bulk polymerization were observed, however the thermomechanical properties of these polymers can be modulated using different monomer ratios.

\section{Notes and references}

${ }^{a}$ Centre National de la Recherche Scientifique, Laboratoire de Chimie des Polymères Organiques, UMR 5629, F-33607 Pessac Cedex, France.

$b$ Université de Bordeaux, Laboratoire de Chimie des Polymères Organiques, UMR 5629, F-33607 Pessac Cedex, France

${ }^{c}$ ITERG, 11 rue Gaspard Monge, Parc Industriel, Pessac Cedex, F-33600, France

$\dagger \quad \log \mathrm{P}$ and $\log \mathrm{S}$ can be calculated using ALOGPS 2.1 software online: VCCLAB, Virtual Computational Chemistry Laboratory, http://www.vcclab.org, 2005 (accessed in March 2013). The $\log P$ and $\log \mathrm{S}$ values of RicBmE are lower than hexadecane but in the same range as decane: $\log \mathrm{P}=6.13$ and $\log \mathrm{S}=-5.34$.

1. M. Muro-Small and D. Neckers, ACS Sustain. Chem. Eng., 2013, 1, 1214-1217.

2. U. Biermann, U. Bornscheuer, M. A. R. Meier, J. O. Metzger, and H. J. Schäfer, Angew. Chemie Int. Ed., 2011, 50, 3854-3871.

3. C. Vilela, A. F. Sousa, A. C. Fonseca, A. C. Serra, J. F. J. Coelho, C. S. R. Freirea, and A. J. D. Silvestrea, Polym. Chem., 2014, 5, 3119-3141

4. J. O. Metzger, Eur. J. Lipid Sci. Technol., 2009, 111, 865-876.

5. Y. Xia and R. C. Larock, Green Chem., 2010, 12, 1893-1909.

6. L. Maisonneuve, T. Lebarbé, E. Grau, and H. Cramail, Polym. Chem., 2013, 4, 5472-5517.

7. M. Desroches, M. Escouvois, R. Auvergne, S. Caillol, and B. Boutevin, Polym. Rev., 2012, 52, 38-79.

8. E. Del Rio, G. Lligadas, J. C. Ronda, M. Galià, M. A. R. Meier, and V. Cádiz, J. Polym. Sci. Part A Polym. Chem., 2011, 49, 518525.

9. Z. S. Petrović, D. Hong, I. Javni, N. Erina, Z. Fan, J. Ilavský, and F. Zhang, Polymer, 2013, 54, 372-380.

10. M. F. Sonnenschein, V. V Ginzburg, K. S. Schiller, and B. L. Wendt, Polymer, 2013, 54, 1350-1360.

11. K. I. Suresh, ACS Sustain. Chem. Eng., 2013, 1, 232-242.

12. A. More, L. Maisonneuve, T. Lebarbé, B. Gadenne, C. Alfos, and H. Cramail, Eur. J. Lipid Sci. Technol., 2013, 115, 61-75.

13. A. More, T. Lebarbé, and L. Maisonneuve, Eur. Polym. J., 2013, 49, 823-833.

14. C. Fu, Z. Zheng, Z. Yang, Y. Chen, and L. Shen, Prog. Org. Coatings, 2013, 77, 53-60. 
15. L. Raghunanan, J. Yue, and S. Narine, J. Am. Oil Chem. Soc., 2013, 1-8.

16. D. Dieterich, Prog. Org. Coatings, 1981, 9, 281-340.

17. T. F. Garrison, M. R. Kessler, and R. C. Larock, Polymer, 2014, 55, 1004-1011.

18. J. Bullermann, S. Friebel, T. Salthammer, and R. Spohnholz, Prog. Org. Coatings, 2013, 76, 609-615.

19. Y. Li, A. J. Noordover, R. A. T. M. van Benthem, and C. E. Koning, Eur. Polym. J., 2014, 52, 12-22.

20. Y. Li, B. A. J. Noordover, R. A. T. M. van Benthem, and C. E. Koning, ACS Sustain. Chem. Eng., 2014, 2, 788-797.

21. K. Landfester, F. Tiarks, H.-P. Hentze, and M. Antonietti, Macromol. Chem. Phys., 2000, 201, 1-5.

22. F. Tiarks, K. Landfester, and M. Antonietti, J. Polym. Sci. Part A Polym. Chem., 2001, 39, 2520-2524.

23. C.-Y. Li, Y.-H. Li, K.-H. Hsieh, and W.-Y. Chiu, J. Appl. Polym. Sci., 2008, 107, 840-845.

24. B. G. Zanetti-Ramos, E. Lemos-Senna, V. Soldi, R. Borsali, E. Cloutet, and H. Cramail, Polymer, 2006, 47, 8080-8087.

25. A. Valério, S. R. P. da Rocha, P. H. H. Araújo, and C. Sayer, Eur. J. Lipid Sci. Technol., 2014, 116, 24-30.

$26 . \quad$ B. G. Zanetti-Ramos, E. Lemos-Senna, H. Cramail, E. Cloutet, R. Borsali, and V. Soldi, Mater. Sci. Eng. C, 2008, 28, 526-531.

27. Z. Qian, J. Chen, Y. Chen, Z. Zhang, and H. Liu, Colloids Surfaces A Physicochem. Eng. Asp., 2007, 295, 7-15.

28. M. Manguian, M. Save, C. Chassenieux, and B. Charleux, Colloid Polym. Sci., 2005, 284, 142-150.

29. G. Baskar, K. Landfester, and M. Antonietti, Macromolecules, 2000, 33, 9228-9232.

30. A. Chakrabarty and N. K. Singha, J. Colloid Interface Sci., 2013, 408, 66-74.

31. D. V. Palaskar, A. Boyer, E. Cloutet, J.-F. Le Meins, B. Gadenne, C. Alfos, C. Farcet, and H. Cramail, J. Polym. Sci. Part A Polym. Chem., 2012, 50, 1766-1782.

32. I. V Tetko, J. Gasteiger, R. Todeschini, A. Mauri, D. Livingstone, P. Ertl, V. a Palyulin, E. V Radchenko, N. S. Zefirov, A. S. Makarenko, V. Y. Tanchuk, and V. V Prokopenko, J. Comput. Aided. Mol. Des., 2005, 19, 453-63.

33. S. Zhang, L. Cheng, and J. Hu, J. Appl. Polym. Sci., 2003, 90, $257-$ 260. 


\section{Electronic Supporting information: \\ Hydrophobe-free miniemulsion polymerization: towards high solid content of fatty acid-based poly(urethane-urea)s latexes}

E. Rix,${ }^{a b}$ G. Ceglia, ${ }^{a b}$ J. Bajt,${ }^{a b}$ G. Chollet, ${ }^{c}$ V. Heroguez ${ }^{a b}$ E. Grau ${ }^{a b}$ and H. Cramail ${ }^{a b}$

\section{Contents}

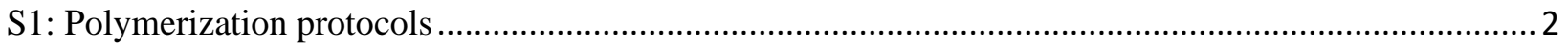

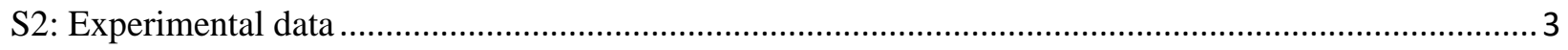

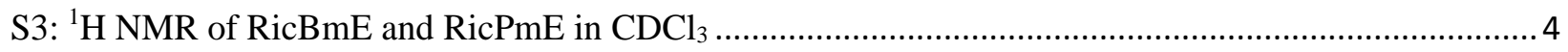

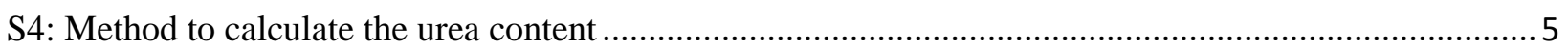

S5: NMR spectra of lyophilized latex and bulk polymers in DMSO ....................................................

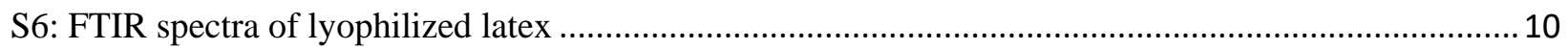

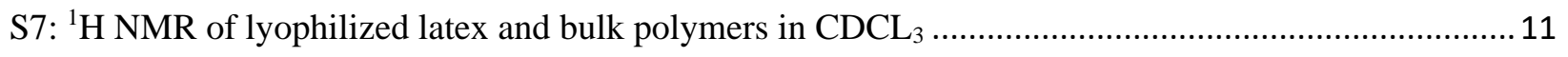

S8: SEC graphs of lyophilized latex and bulk polymers....................................................................... 13

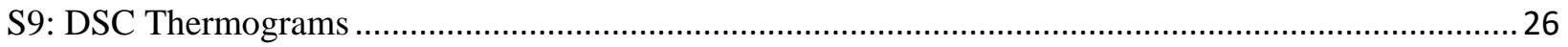




\section{$\underline{\text { S1: Polymerization protocols }}$}

\section{Bulk polymerization:}

Both monomers and the catalyst are introduced in a tubular schlenk. The polymerization is performed at $60^{\circ} \mathrm{C}$ under magnetic stirring for $4 \mathrm{~h}$. The stirring is no more efficient when the viscosity of the mixture increases. Then the oil bath is removed and samples are taken for analysis.

\section{Miniemulsion polymerization:}

\section{Preparation of the aqueous phase:}

Sodium dodecyl sulfate is dissolve in deionized water under magnetic stirring until complete dissolution.

\section{Preparation of the organic phase and emulsification:}

Both monomers and the catalyst are stirred manually with a spatula for about 10s. The organic phase is then introduced in the aqueous phase previously prepared. Sonication is applied to the system. During sonication, an ice bath is used to cool the system. An emulsion is obtained.

\section{Polymerization:}

Shortly after emulsification, the emulsion is inserted in a round-bottom flask equipped with a mechanic stirrer at $60^{\circ} \mathrm{C}$. Polymerization is performed for $4 \mathrm{~h}$ at this temperature with a stirring of $300 \mathrm{rpm}$. 


\section{S2: Experimental data}

${ }^{1} \mathrm{H}$ and ${ }^{13} \mathrm{C}-\mathrm{NMR}$ spectra were recorded on Bruker Avance 400 spectrometer.

Size exclusion chromatography (SEC) analyses were performed in THF $\left(40^{\circ} \mathrm{C}\right)$ on a PL-GPC 50 plus Integrated GPC from Polymer laboratories-Varian with a series of four columns from TOSOH (TSKgel TOSOH: HXL-L (guard column 6,0mm ID x 4,0cm L); G4000HXL (7,8mm ID x 30,0cm L) ;G3000HXL (7,8mm ID x 30,0cm L) and G2000HXL (7,8mm ID x 30,0cm L)). The elution of the filtered samples was monitored using simultaneous refractive index and UV detection. The elution times were converted to molar mass using a calibration curve based on low dispersity $\left(\mathrm{M}_{\mathrm{w}} / \mathrm{M}_{\mathrm{n}}\right)$ polystyrene (PS) standards.

Differential scanning calorimetry (DSC) thermograms were measured using a DSC Q100 apparatus from TA instruments. For each sample, two cycles from -50 to $100{ }^{\circ} \mathrm{C}$ (or $120{ }^{\circ} \mathrm{C}$ for higher melting point polyurethanes) at $10{ }^{\circ} \mathrm{C} \cdot \mathrm{min}^{-1}$ were performed and then the glass transition temperatures were calculated from the second heating run.

\begin{tabular}{|c|c|c|c|c|c|c|}
\hline Entry & $\begin{array}{c}\mathrm{NCO} / \mathrm{OH} \\
\text { ratio }\end{array}$ & $\begin{array}{c}\mathbf{M w}^{\mathrm{a}, \mathrm{d}} \\
(\mathrm{kg} / \mathrm{mol})\end{array}$ & $\boldsymbol{Ð}^{\mathrm{a}, \mathrm{d}}$ & $\begin{array}{c}\text { Particle } \\
\text { size }^{\mathrm{b}}(n m)\end{array}$ & $\mathbf{T g}^{\mathrm{c}, \mathrm{d}}\left({ }^{\circ} C\right)$ & $\begin{array}{c}\text { Urea } \\
\text { content }^{\mathrm{d}} \\
(\%)\end{array}$ \\
\hline ME0[YP40] & 0.8 & $3.2[9.6]$ & $1.3[1.1]$ & $249 \pm 11$ & $-16[-12]$ & $21[5]$ \\
\hline ME1[YP41] & $\mathbf{1}$ & $3.7[38.2]$ & $1.4[3.5]$ & $238 \pm 19$ & $-5[14]$ & $24[-]^{\mathrm{e}}$ \\
\hline ME2[YP42] & 1.2 & $4.8[24.5]$ & $1.5[2.3]$ & $243 \pm 7$ & $9[12]$ & $30[-]^{\mathrm{e}}$ \\
\hline ME3[YP43] & 1.5 & $5.8[9.6]$ & $1.6[1.7]$ & $226 \pm 14$ & $32[-9]$ & $34[18]$ \\
\hline ME4[YP44] & 1.8 & $5.2[2]$ & $1.5[1.4]$ & $239 \pm 18$ & $69[-22]$ & $43[22]$ \\
\hline ME5[YP45] & 2 & $4.7[2]$ & $1.5[1.4]$ & $228 \pm 16$ & $69[-29]$ & 55 [25] \\
\hline ME8 & 2.5 & 4.2 & 1.4 & $232 \pm 14$ & nd & 55 \\
\hline ME9 & 3 & nd & nd & $220 \pm 6$ & nd & 55 \\
\hline
\end{tabular}

RicPmE and IPDI were used as monomers, with 3.5 CMC of SDS. No hydrophobic agent was added. DBTDL concentration was $0.4 \mathrm{wt} \%$ of the organic phase

${ }^{a}$ Measured by SEC in THF calibrated with polystyrene standards. ${ }^{b}$ Measured by DLS with a $90^{\circ}$ angle. The value given is the average value of three measurements. Polydispersity indexes are between 0.162 and $0.234 .{ }^{c}$ Measured by differential scanning calorimetry. ${ }^{\mathrm{d}}$ Polymers insoluble in deuterated DMSO. $n d$ : not determined 


\section{S3: ${ }^{1} \mathrm{H}$ NMR of RicBmE and RicPmE in $\mathrm{CDCl}_{3}$}

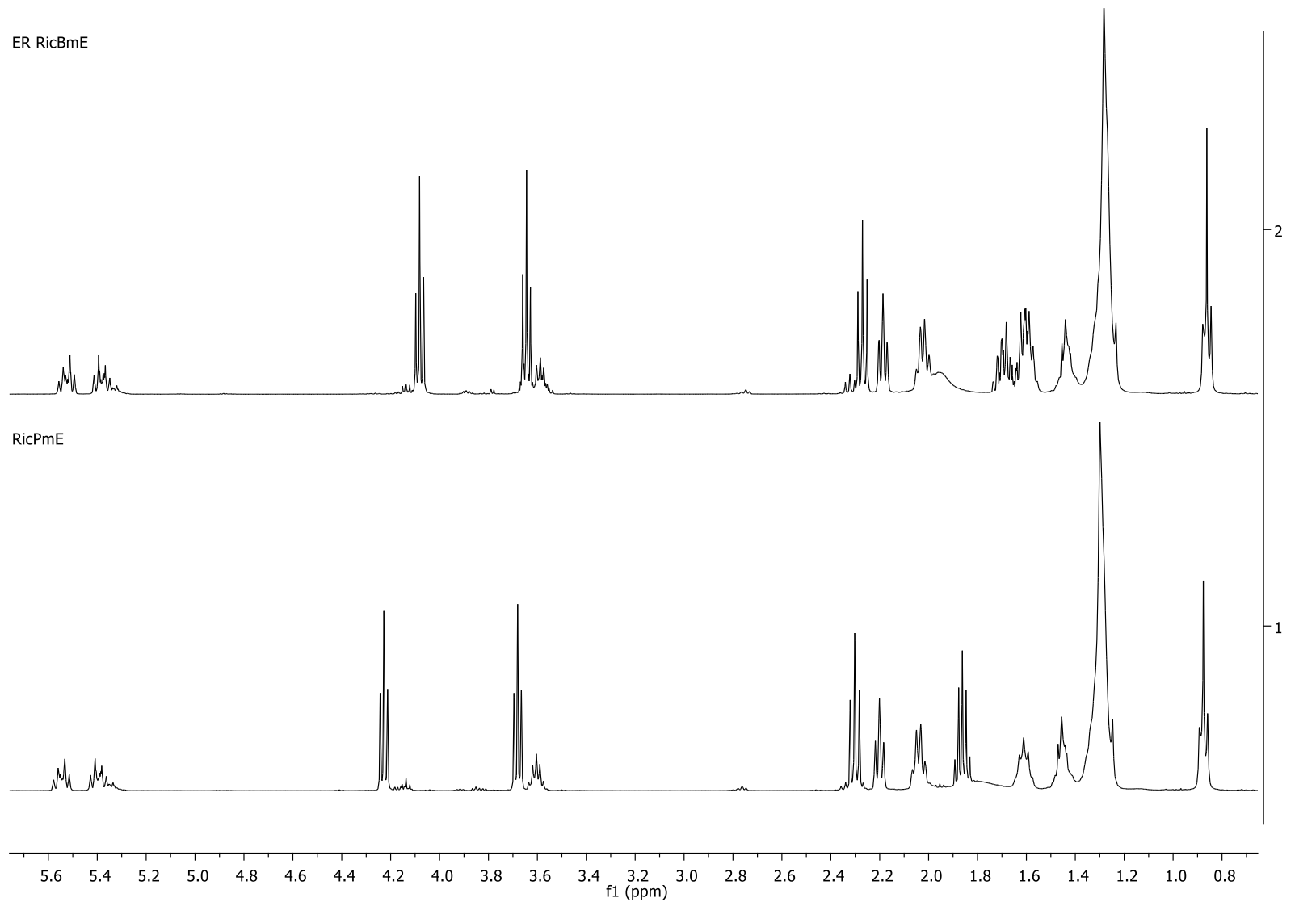




\section{S4: Method to calculate the urea content}

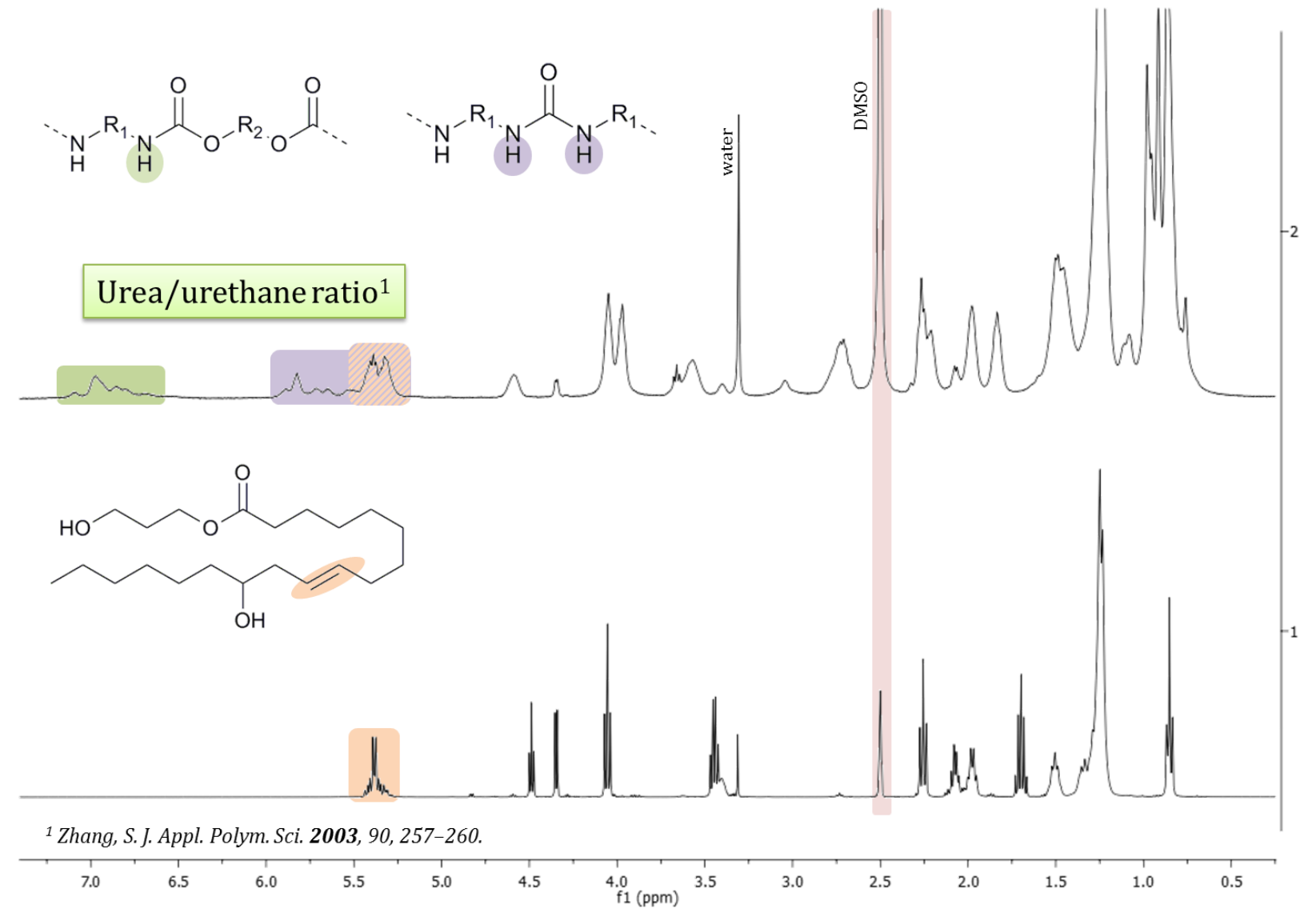

Figure 1: NMR Spectra in DMSO of a lyophilized latex and of RicPmE

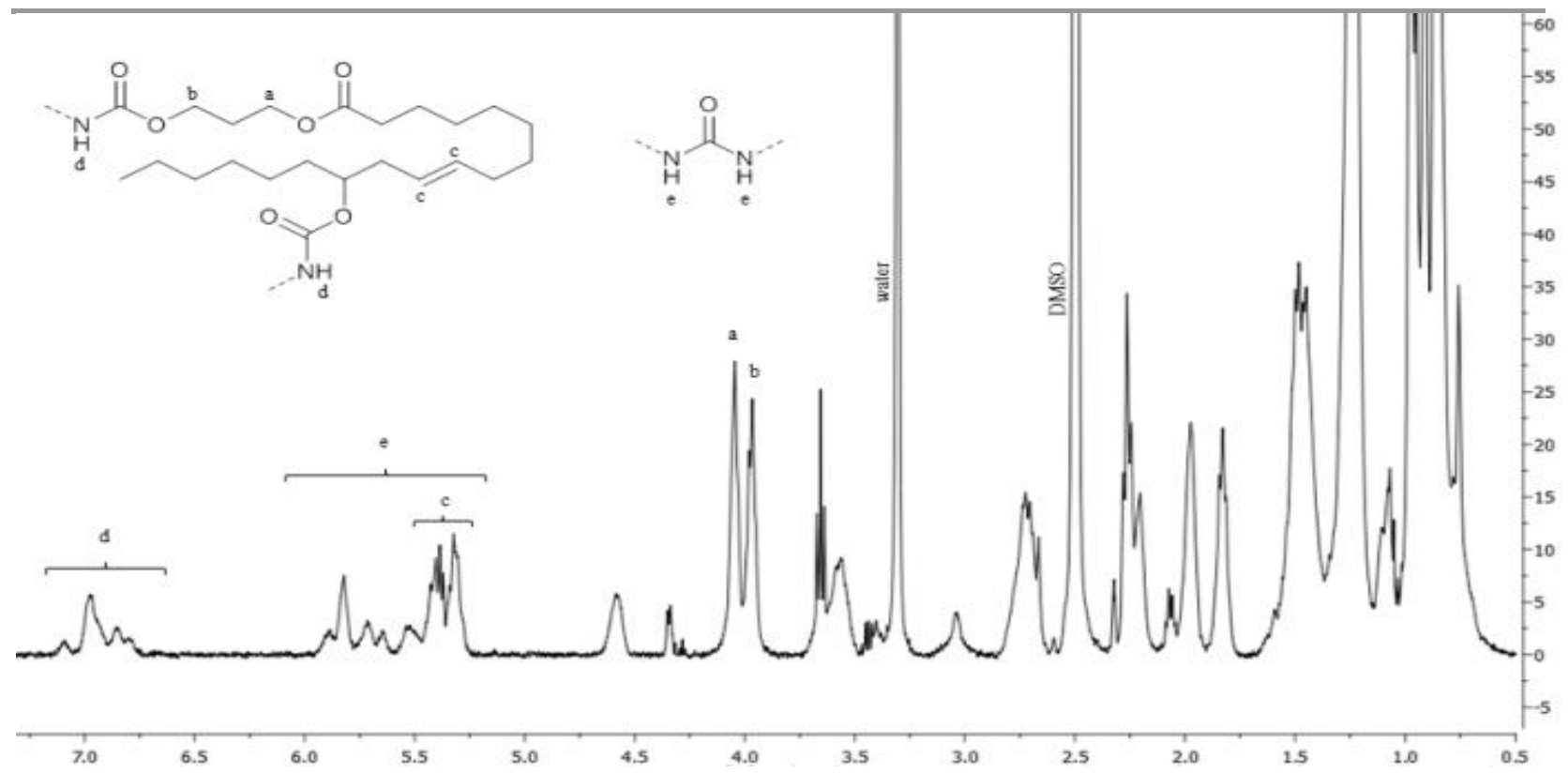


Figure 2: NMR Spectra in DMSO of a lyophilized latex

$$
\text { Urea content }=\frac{\text { urea }}{\text { urea }+ \text { urethane }}
$$

Where:

- $\quad$ urethane $=d$

- $\quad$ urea $=\frac{(c+e)-(a+b+2 f) / 2}{2}$

\section{Equation 1: Definition of the urea content}

$\mathrm{a}, \mathrm{b}, \mathrm{c}, \mathrm{d}$, e and $\mathrm{f}$ are the integrals corresponding to the following peaks: $\mathrm{f}$ is the integral of the peak at $4.49 \mathrm{ppm}$ corresponding to the proton of the unreacted primary alcohol of RicPmE. $\mathrm{f}=0$ when there is no more unreacted primary alcohol.

$\mathrm{a}+\mathrm{b}$ is set to 4 , as it corresponds to 4 protons.

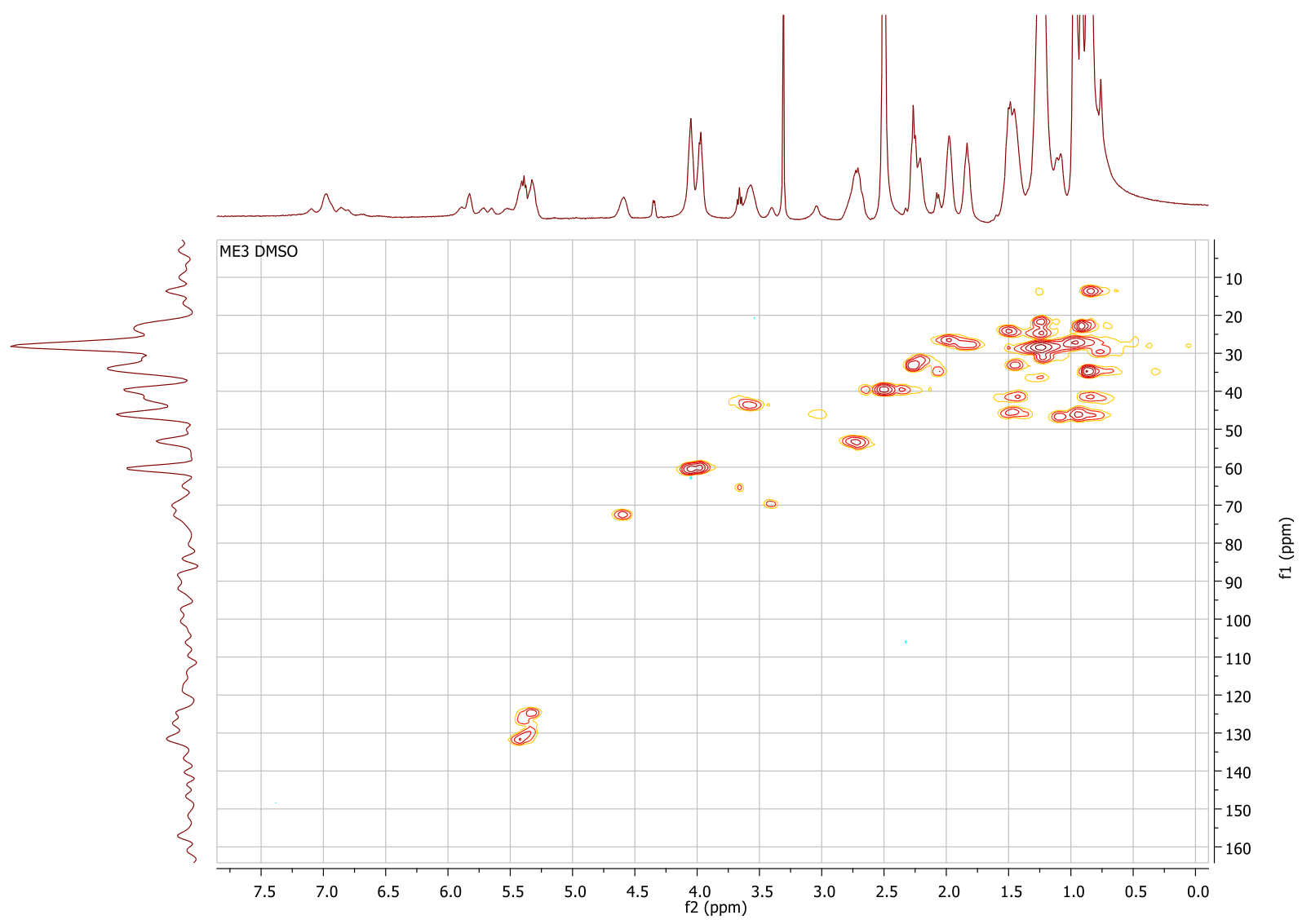

Figure 3: $13 \mathrm{C}-1 \mathrm{H}$ NMR of a lyophilized latex in DMSO.

It shows that the protons between 5 and $7.5 \mathrm{ppm}$ are not linked to a carbon atom. Only the protons of the double bond are visible in this range 


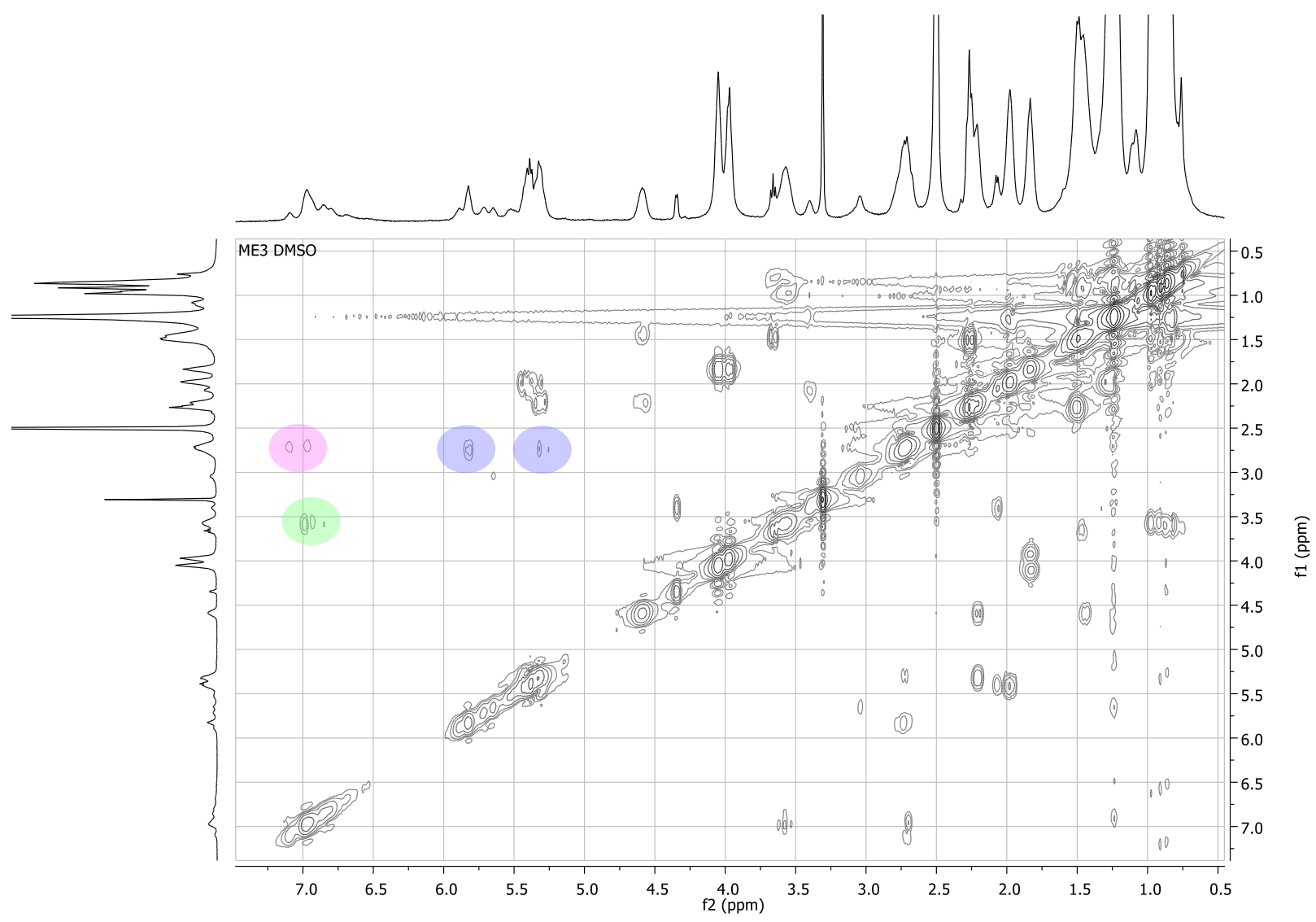

Figure 4: $1 \mathrm{H}-1 \mathrm{H}$ NMR spectrum in DMSO of a lyophilized latex

Around 7ppm (X axis), two correlation signals appear (in pink and green): they correspond to the proton of the NH of urethane functions. There are two signals because of the asymmetrical structure of IPDI.<smiles>C[N-]C1CC(C)(C)CC(C)(CNC(=O)OC)C1</smiles><smiles>CNCC1(C)CC(NC(=O)OC)CC(C)(C)C1</smiles>

Between 5 and $6 p p m$ ( $X$ axis), signals corresponding to the double bond protons are visible. Two signals are visible (in blue), they correspond to the urea formed with the structure below.<smiles>CNC1CC(CNC(=O)CNCC2(C)CC(NC)CC(C)(C)C2)CC(C)(C)C1</smiles>

Two other urea structures could be formed, but they are not visible on the NMR spectra. This can be explained by the different reactivity of the two isocyanate functions of the IPDI due to steric hindrance. The more reactive functions react with alcohols, then the less reactive with the alcohol functions remaining. Thus, when the side reaction of isocyanate and water occurs, the less reactive isocyanate function is the main one remaining. 


\section{S5: NMR spectra of lyophilized latex and bulk polymers in DMSO}

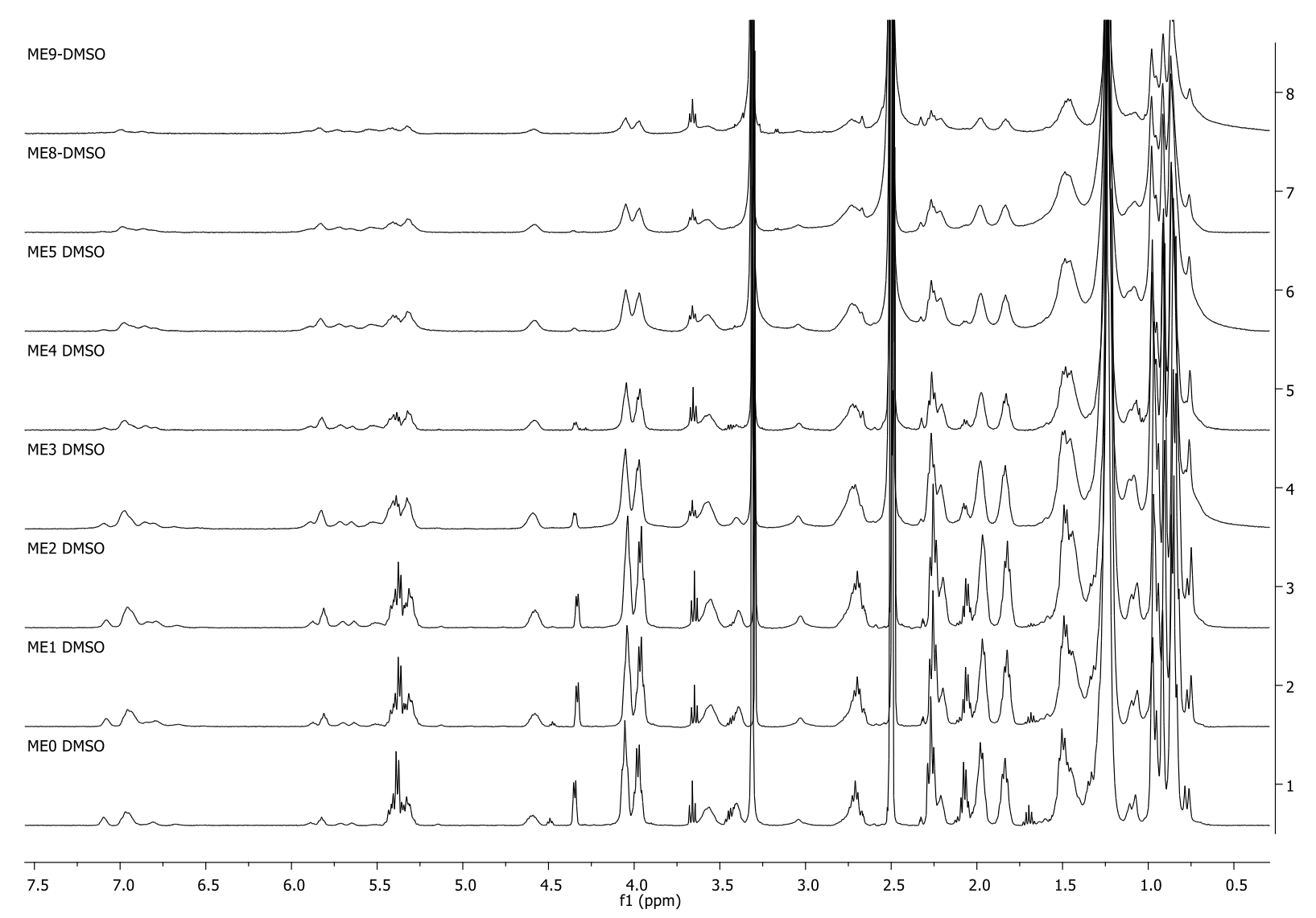

Figure 2: NMR spectra of lyophilized latex MEO to ME9 in DMSO 


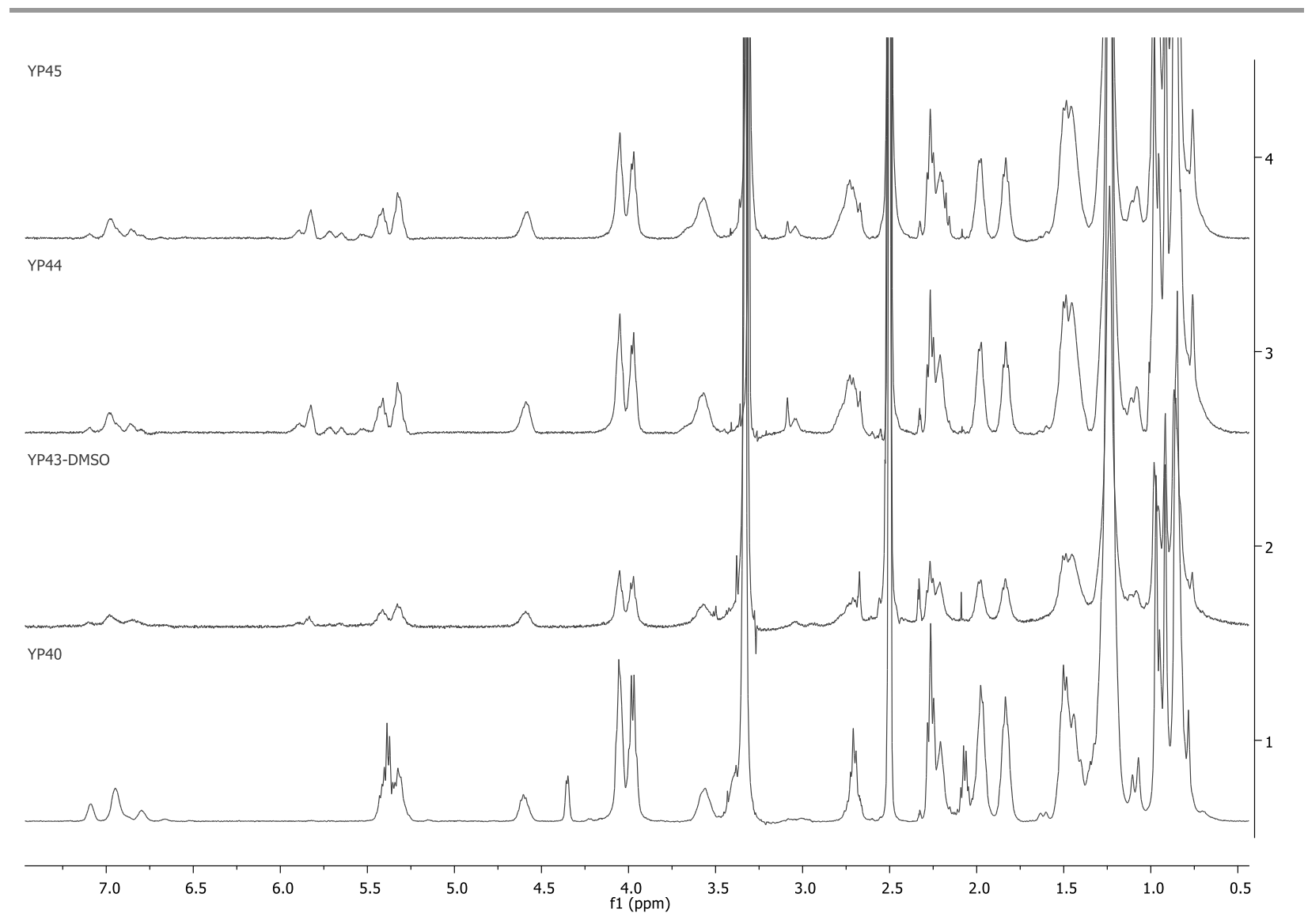

Figure 3: NMR spectra of bulk polymers in DMSO 


\section{S6: FTIR spectra of lyophilized latex}

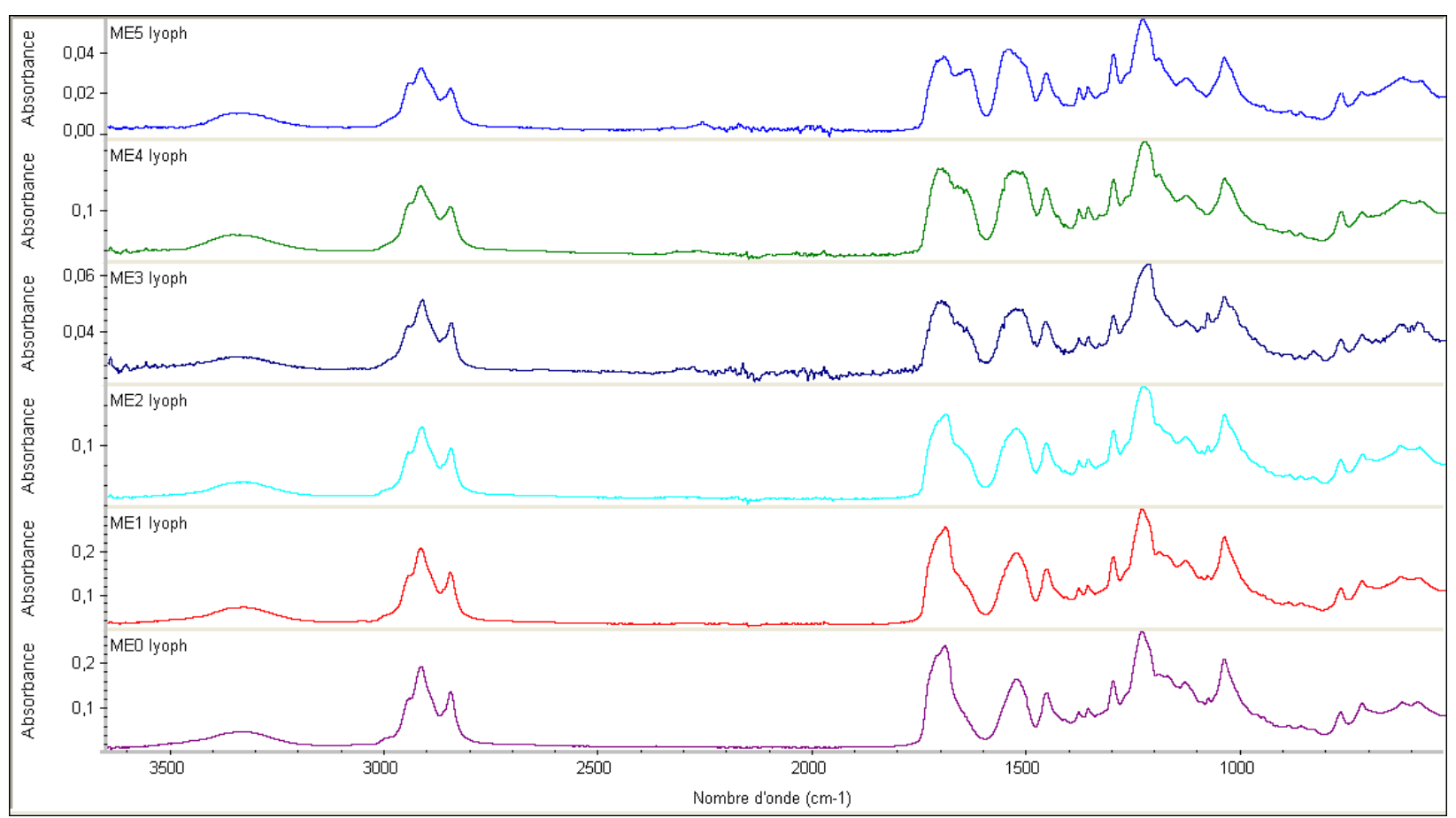

The peak at $1645 \mathrm{~cm}-1$ is due to the carbonyl group of urea. The peak at $1700 \mathrm{~cm}-1$ is due to the carbonyl group of urea. Urea increases with the amount of IPDI introduced which is in accordance with the urea contents calculated from $1 \mathrm{H}$ NMR. 


\section{S7: ${ }^{1} \mathrm{H}$ NMR of lyophilized latex and bulk polymers in $\mathrm{CDCL}_{3}$}

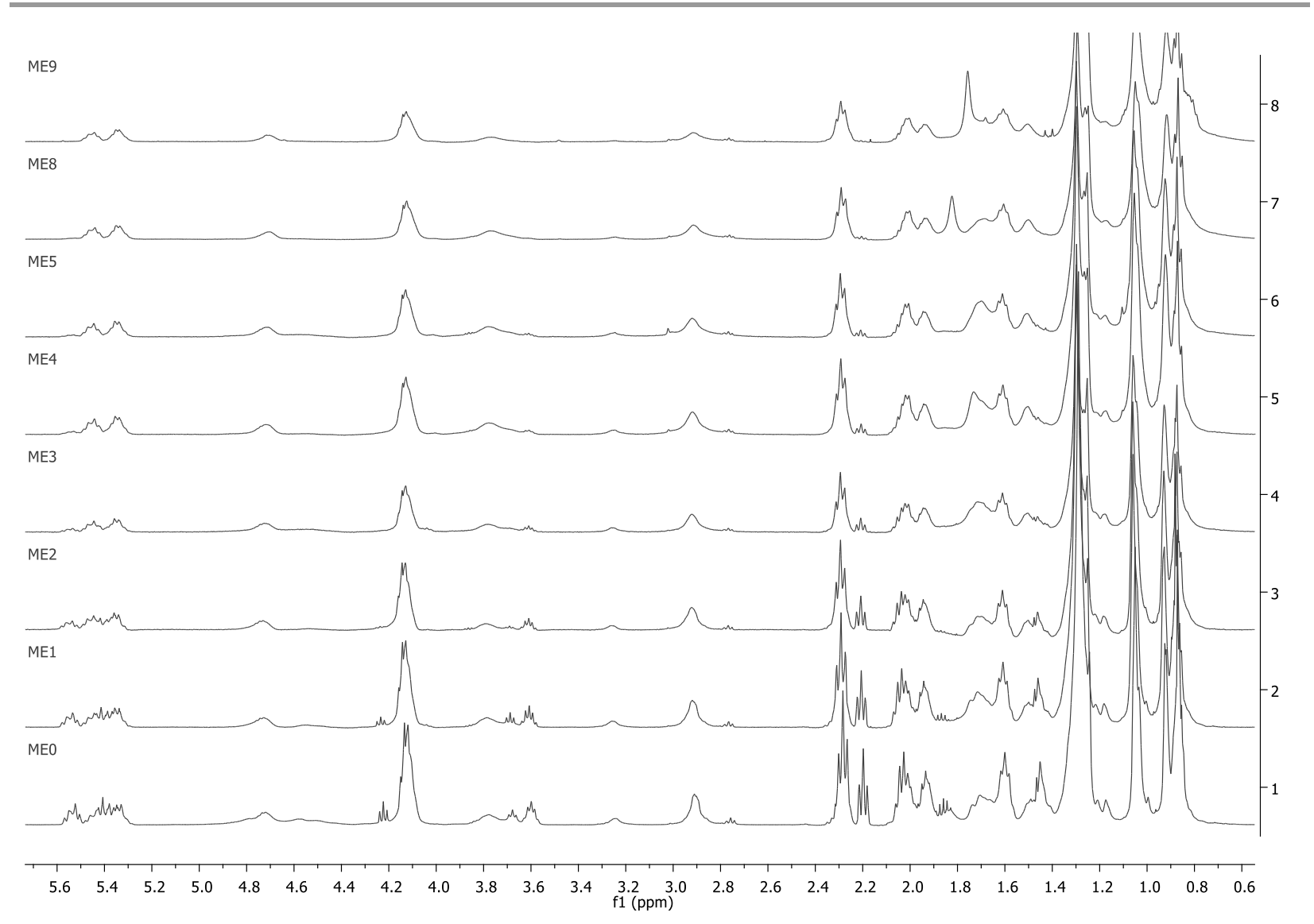

Figure 4: NMR spectra of lyophilized latex MEO to ME9 in $\mathrm{CDCl} 3$ 


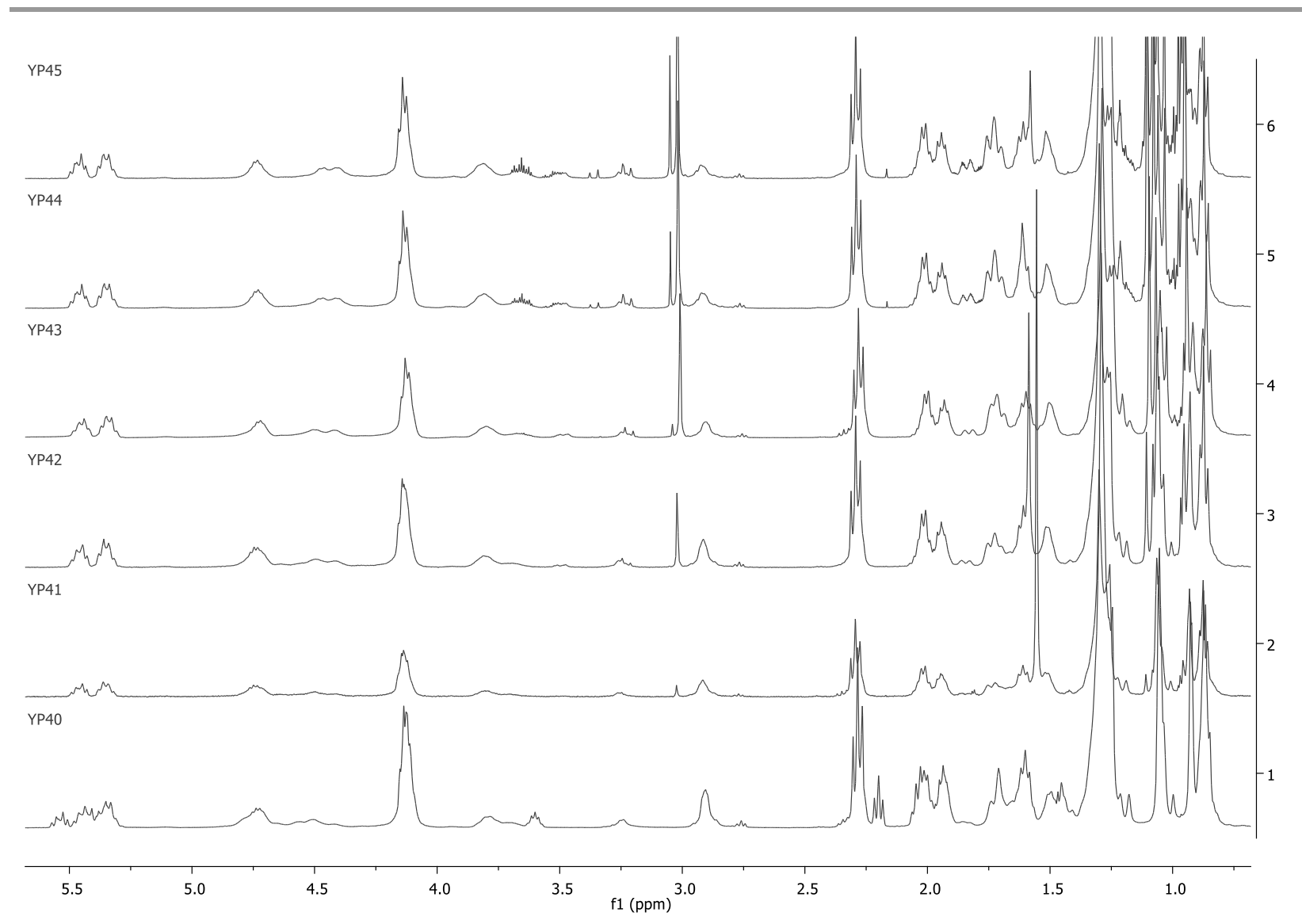

Figure 5: NMR spectra of bulk polymers in $\mathrm{CDCl}_{3}$ 


\section{S8: SEC graphs of lyophilized latex and bulk polymers \\ ME0}

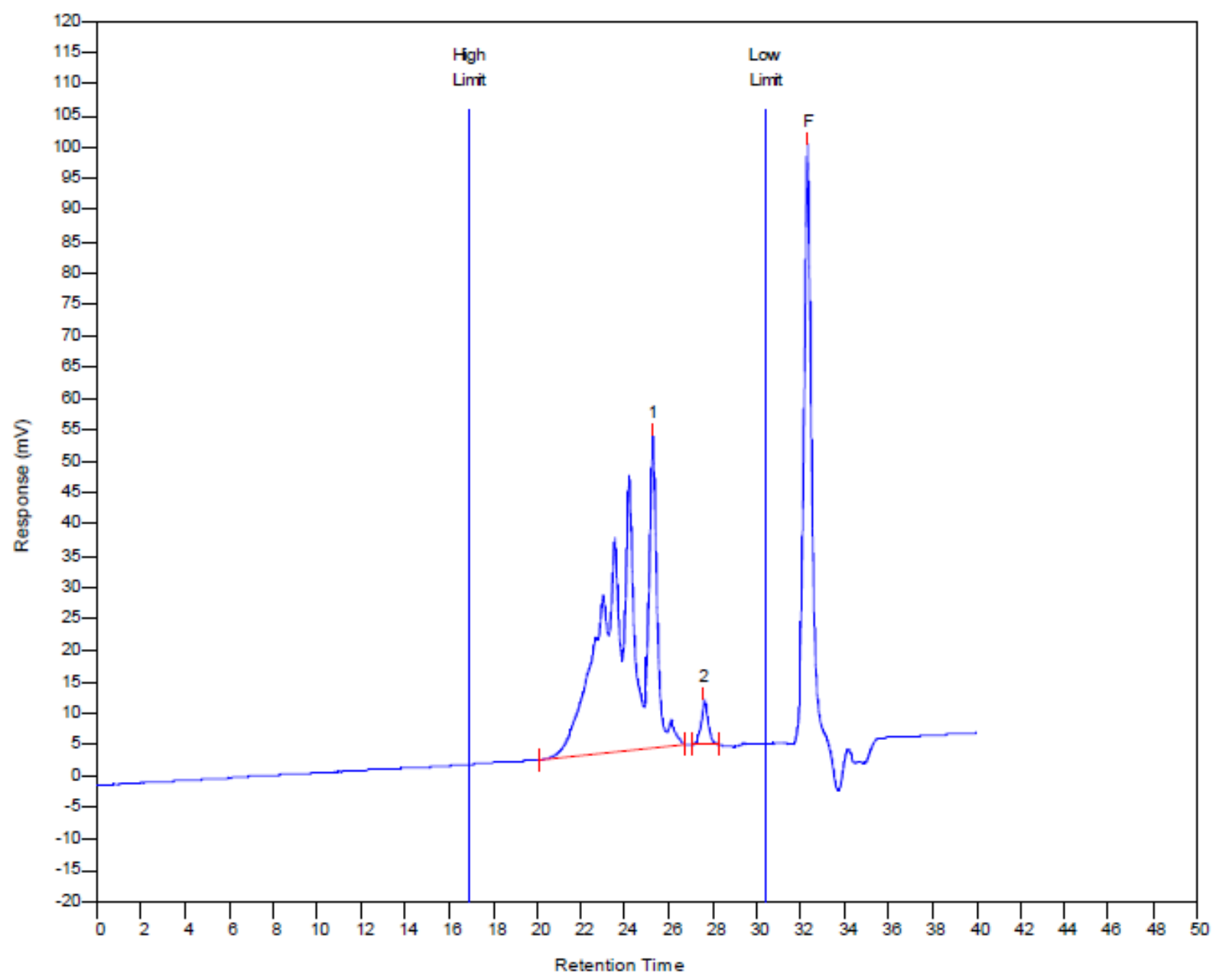

MW Averages

\begin{tabular}{rrrrrrrr} 
Peak No & \multicolumn{1}{c}{$\mathrm{Mp}$} & \multicolumn{1}{c}{$\mathrm{Mn}$} & $\mathrm{Mw}$ & $\mathrm{Mz}$ & $\mathrm{Mz}+1$ & \multicolumn{1}{c}{$\mathrm{Mv}$} & $\mathrm{PD}$ \\
1 & 1491 & 2406 & 3166 & 4282 & 5674 & 3027 & 1.31588 \\
2 & 583 & 580 & 583 & 586 & 589 & 582 & 1.00517 \\
3 & 0 & 0 & 0 & 0 & 0 & 0 & 0
\end{tabular}




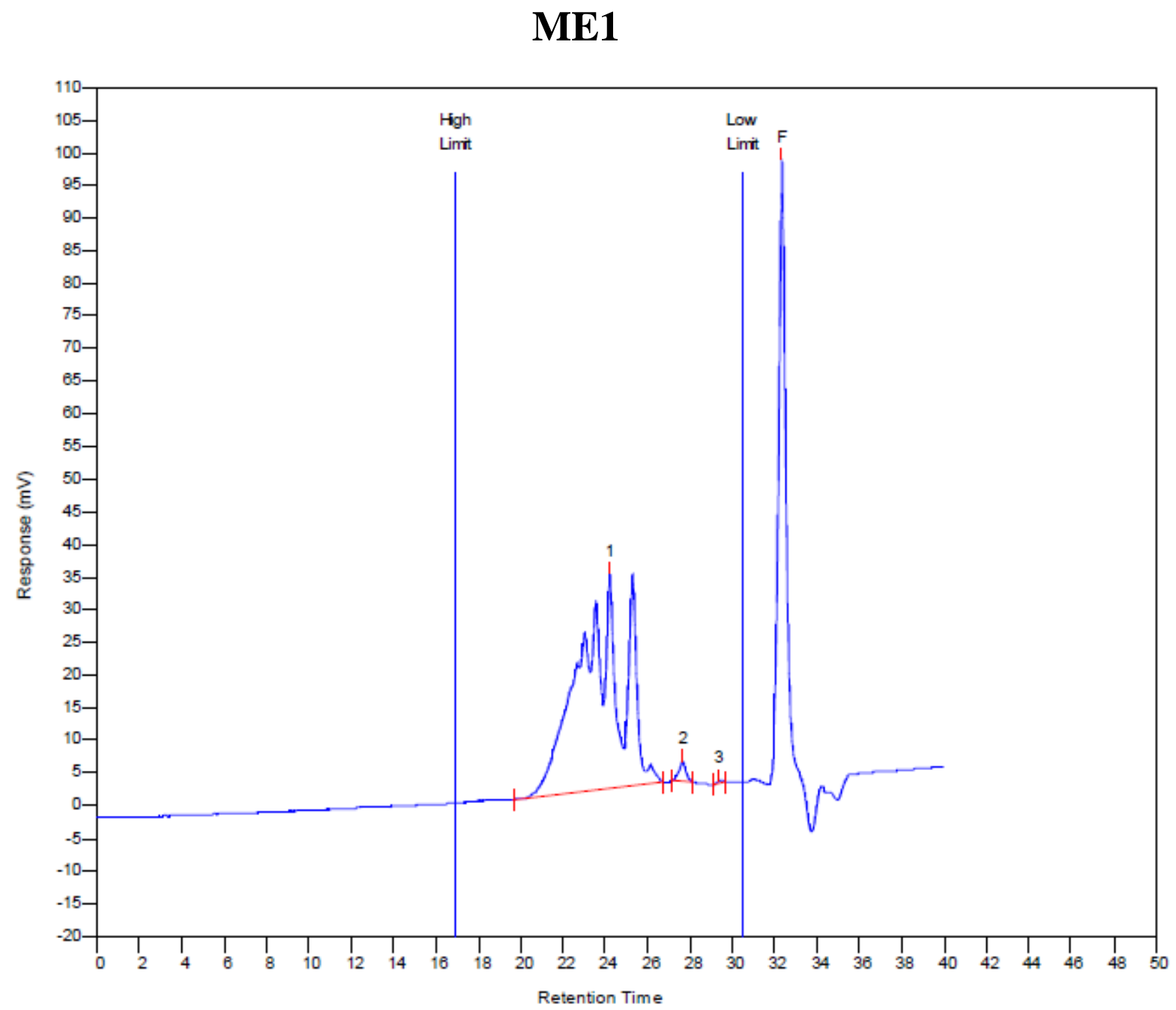

MW Averages

\begin{tabular}{rrrrrrrr} 
Peak No & \multicolumn{1}{c}{ Mp } & Mn & Mw & Mz & Mz+1 & Mv & \multicolumn{1}{c}{ PD } \\
1 & 2345 & 2681 & 3685 & 5136 & 6893 & 3503 & 1.37449 \\
2 & 582 & 588 & 590 & 593 & 595 & 590 & 1.0034 \\
3 & 271 & 273 & 272 & 273 & 274 & 271 & 0.996337 \\
4 & 46 & 44 & 45 & 46 & 47 & 45 & 1.02273
\end{tabular}


ME2

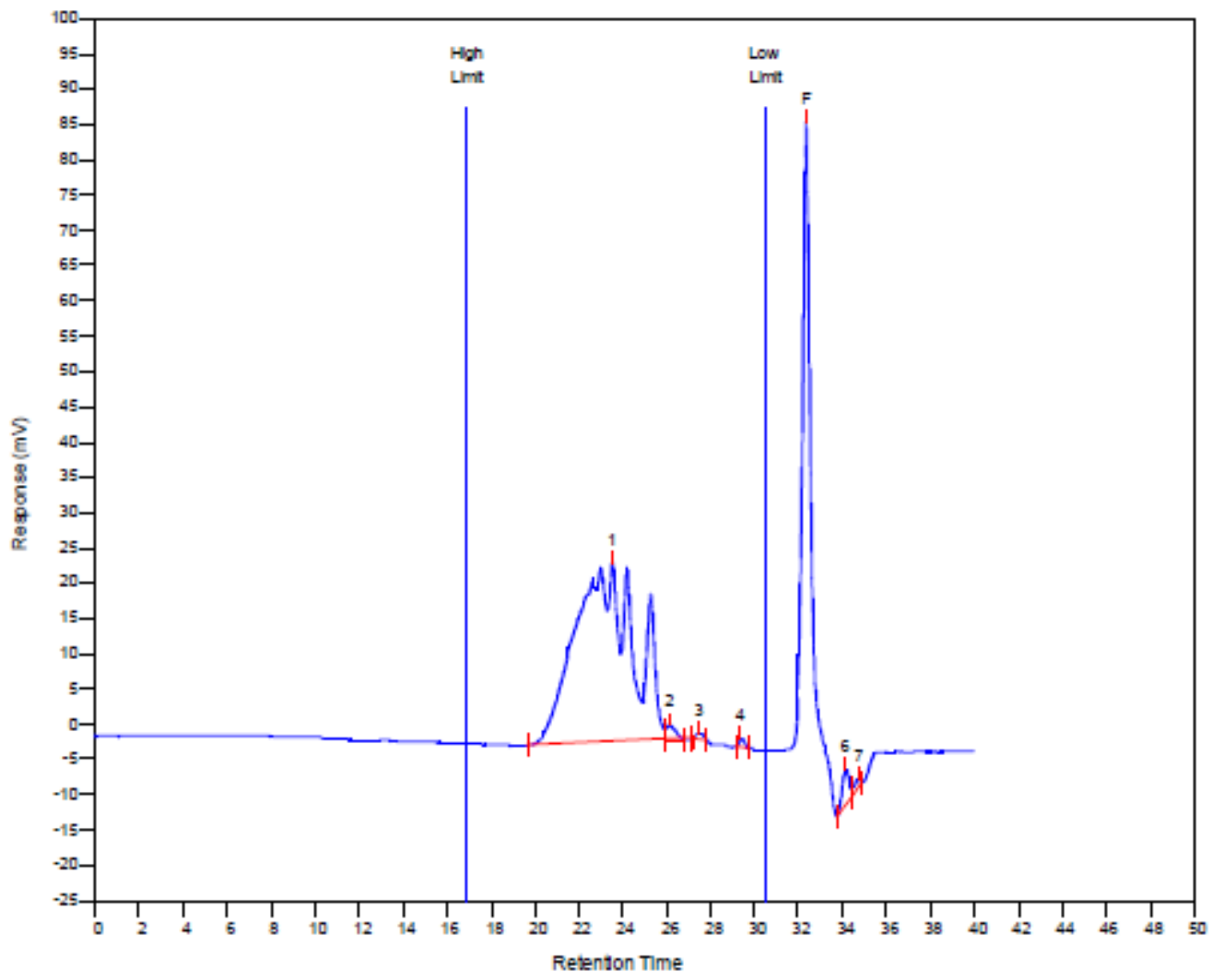

MW Averages

\begin{tabular}{rrrrrrrr} 
Peak No & \multicolumn{1}{c}{ Mp } & \multicolumn{1}{c}{ Mn } & \multicolumn{1}{c}{ Mw } & Mz & Mz+1 & Mv & \multicolumn{1}{c}{ PD } \\
1 & 3201 & 3296 & 4786 & 6973 & 9596 & 4513 & 1.45206 \\
2 & 1082 & 1067 & 1003 & 1044 & 1050 & 988 & 0.940019 \\
3 & 594 & 617 & 617 & 620 & 622 & 616 & 1 \\
4 & 289 & 268 & 268 & 269 & 270 & 268 & 1
\end{tabular}




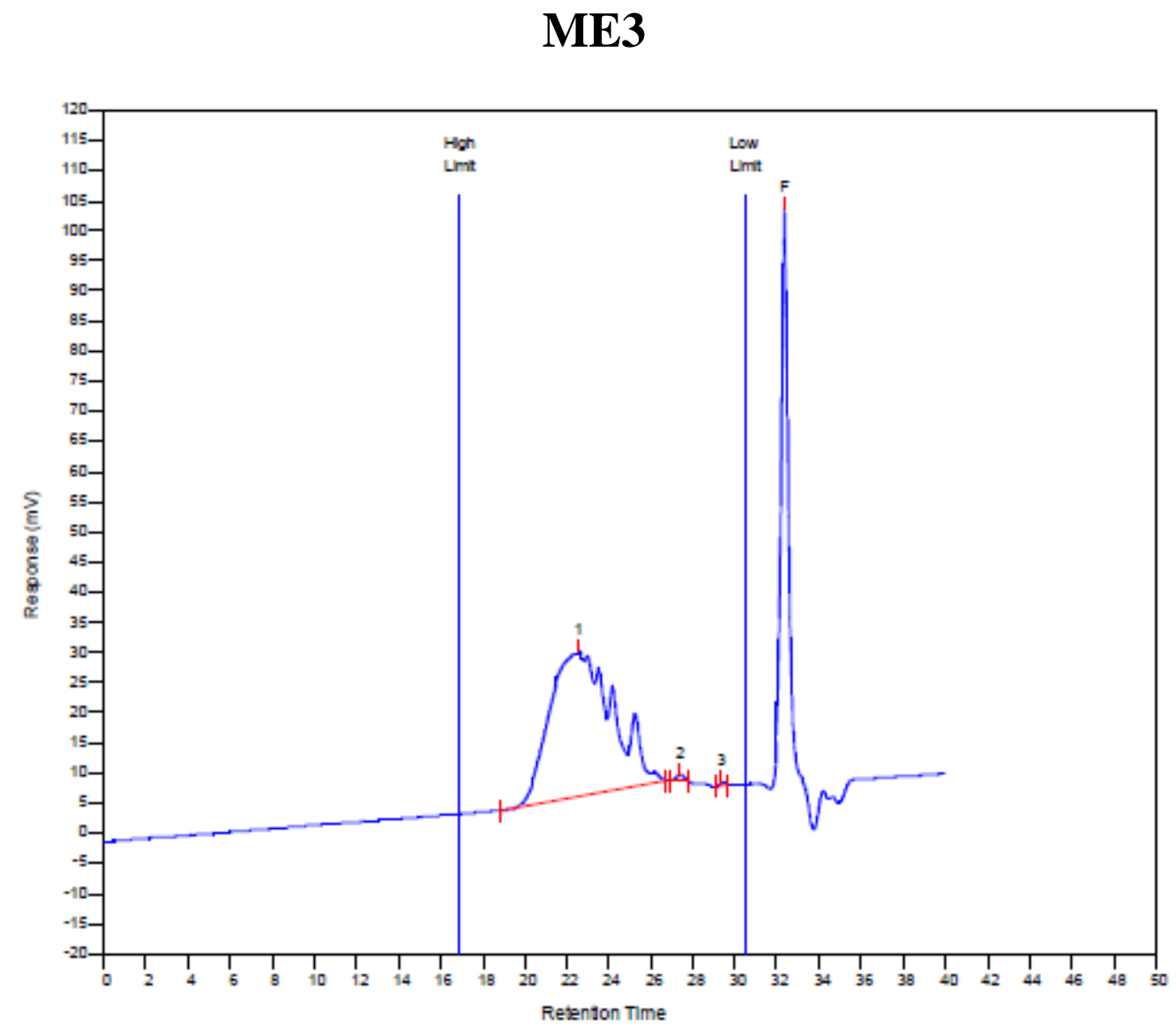

MW Averages

Peak No Mp $\quad \mathrm{Mn} \quad \mathrm{Mw} \quad \mathrm{Mz} \quad \mathrm{Mz}+1 \quad \mathrm{Mv} \quad \mathrm{PD}$

$\begin{array}{rrrrrrrr}1 & 4993 & 3759 & 5845 & 8683 & 11827 & 5480 & 1.55493 \\ 2 & 645 & 652 & 654 & 658 & 661 & 653 & 1.00307 \\ 3 & 289 & 269 & 289 & 270 & 271 & 288 & \end{array}$




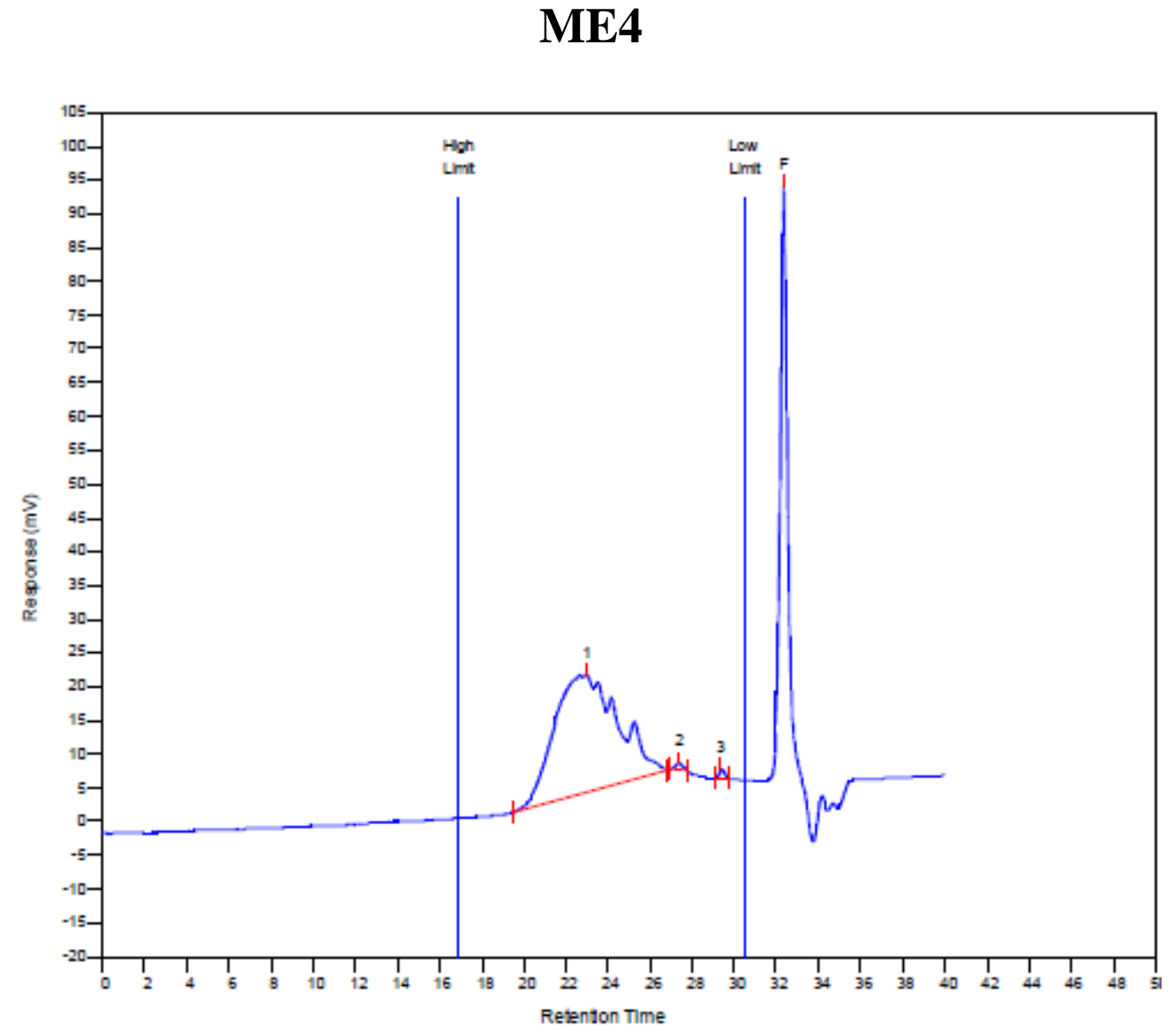

MW Averages

\begin{tabular}{rrrrrrrr} 
Peak No & Mp & Mn & Mw & \multicolumn{1}{c}{ Mz } & Mz+1 & Mv & PD \\
1 & 4993 & 3415 & 5183 & 7654 & 10539 & 4870 & 1.51772 \\
2 & 649 & 660 & 661 & 665 & 668 & 660 & 1.00152 \\
3 & 269 & 268 & 268 & 269 & 270 & 268 & 1
\end{tabular}




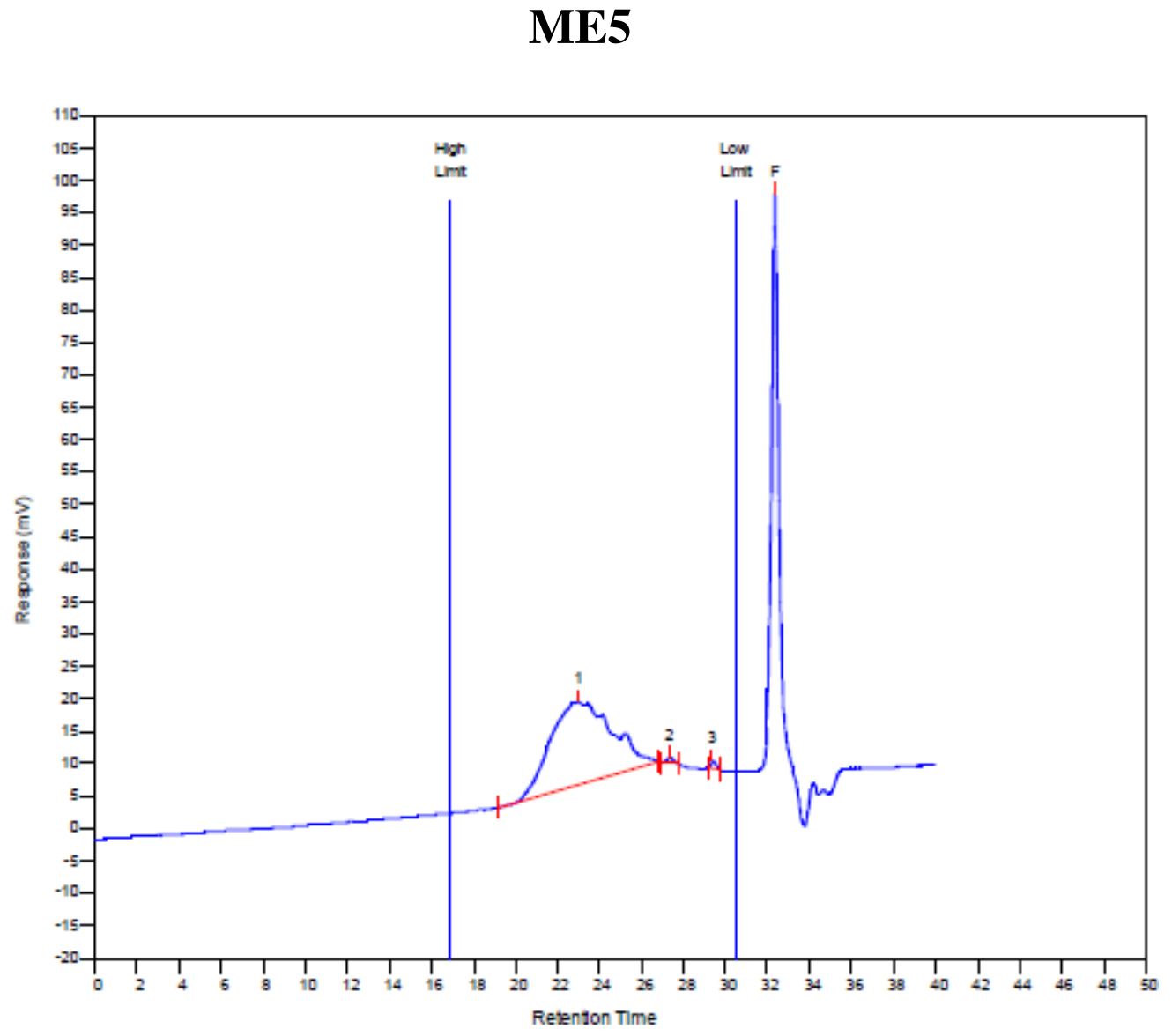

MW Averages

Peak No Mp $\quad \mathrm{Mn} \quad \mathrm{Mw} \quad \mathrm{Mz} \quad \mathrm{Mz}+1 \quad \mathrm{Mv} \quad \mathrm{PD}$

$\begin{array}{llllllll}1 & 4155 & 3192 & 4692 & 6762 & 9155 & 4429 & 1.46992\end{array}$

$\begin{array}{rrrrrrrr}2 & 662 & 657 & 658 & 662 & 664 & 657 & 1.00152 \\ 3 & 269 & 267 & 267 & 268 & 269 & 267 & 1\end{array}$ 


\section{ME8}

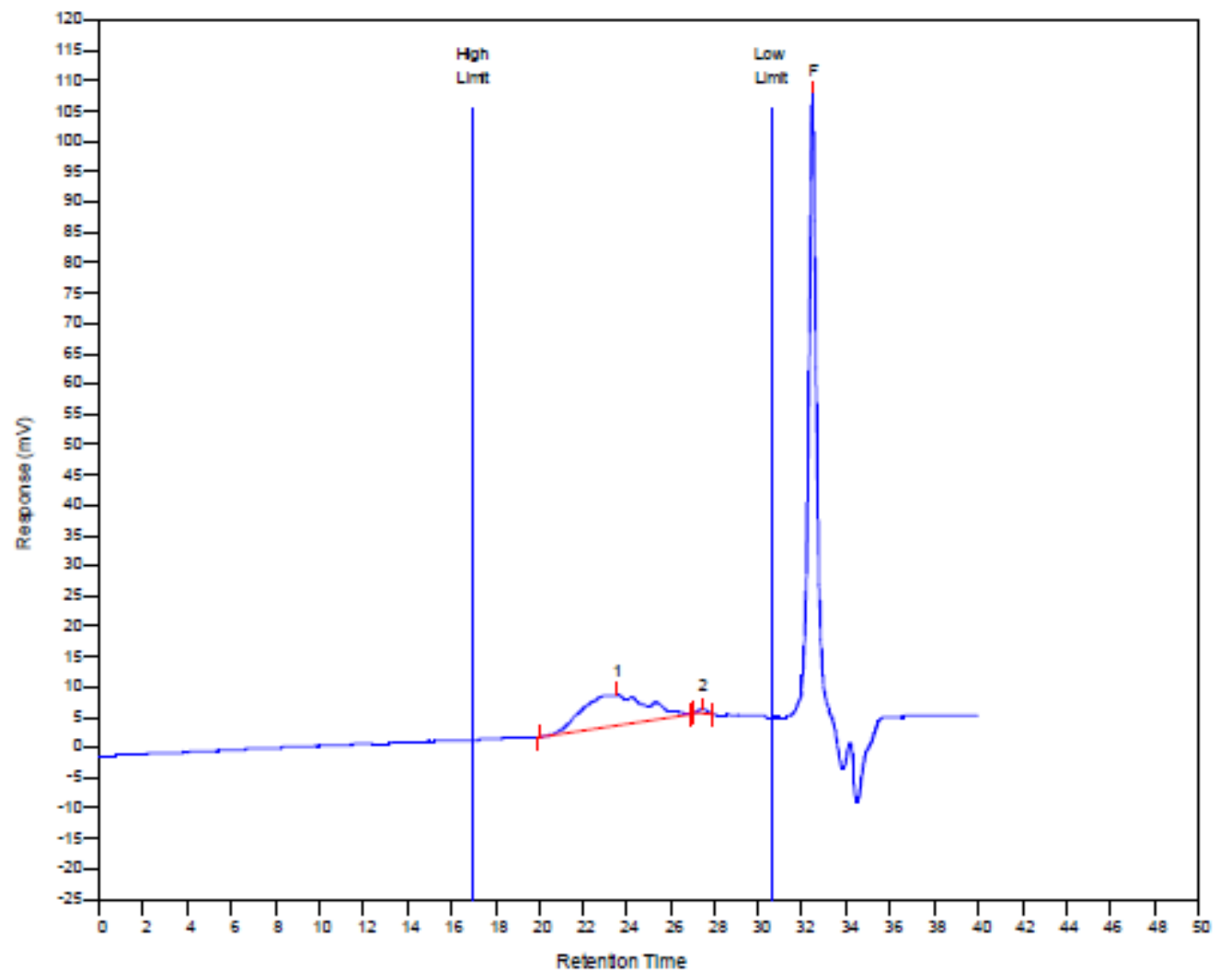

MW Averages

Peak No Mp Mn Mw Mz Mz+1 Mv $\quad M \quad$ PD

$\begin{array}{llllllll}1 & 4064 & 2969 & 4220 & 5854 & 7647 & 4006 & 1.42135\end{array}$

$\begin{array}{llllllll}2 & 663 & 655 & 657 & 661 & 664 & 657 & 1.00305\end{array}$ 


\section{YP40}

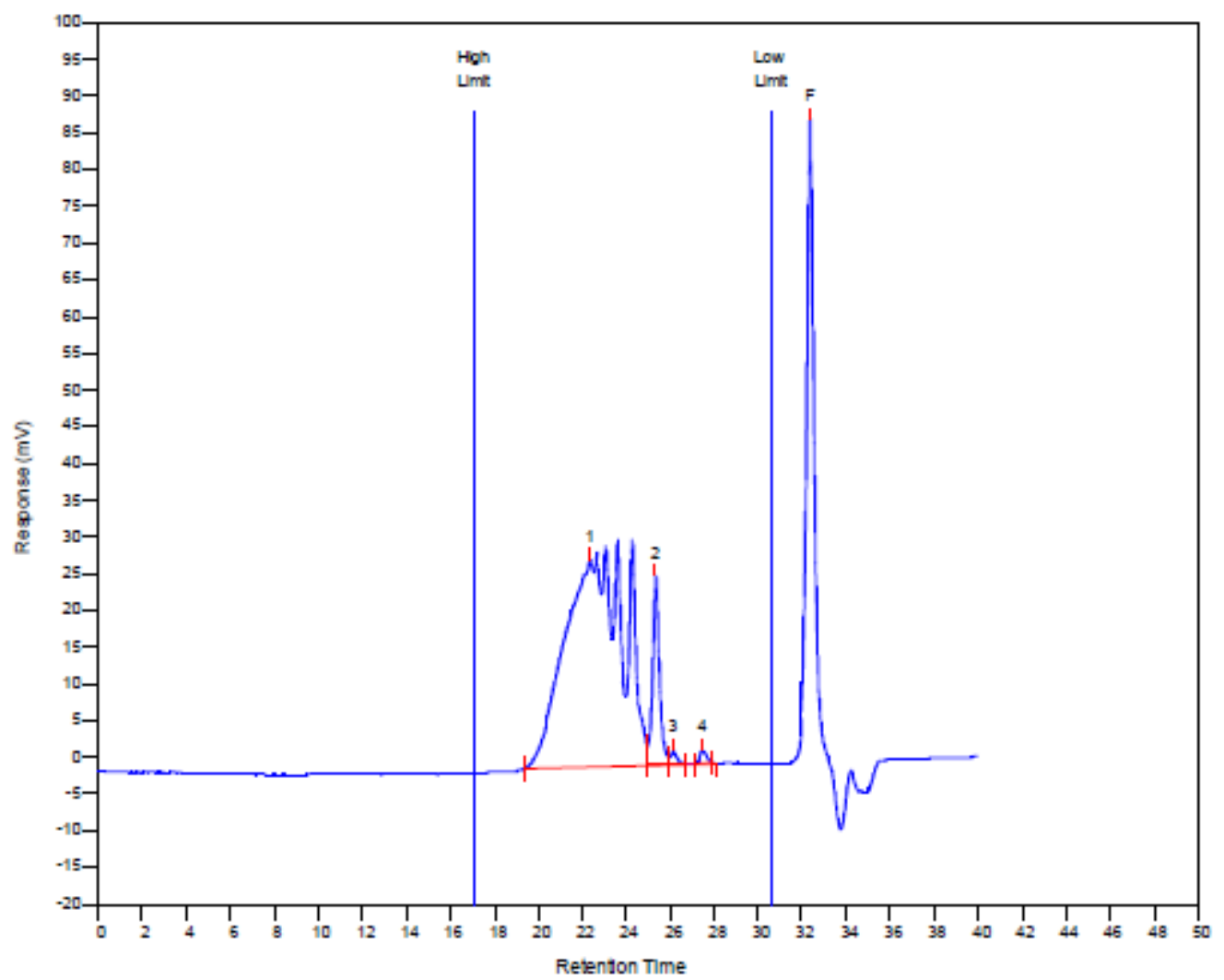

MW Averages

$\begin{array}{rrrrrrrr}\text { Peak No } & \text { Mp } & \text { Mn } & \text { Mw } & \text { Mz } & \text { Mz+1 } & \text { Mv } & \text { PD } \\ 1 & 2347 & 4538 & 6439 & 9413 & 13041 & 6077 & 1.41891 \\ 2 & 1507 & 1505 & 1483 & 1503 & 1509 & 1477 & 0.985382 \\ 3 & 1106 & 1128 & 1053 & 1095 & 1098 & 1037 & 0.933511 \\ 4 & 651 & 639 & 641 & 644 & 646 & 640 & 1.00313\end{array}$




\section{YP41}

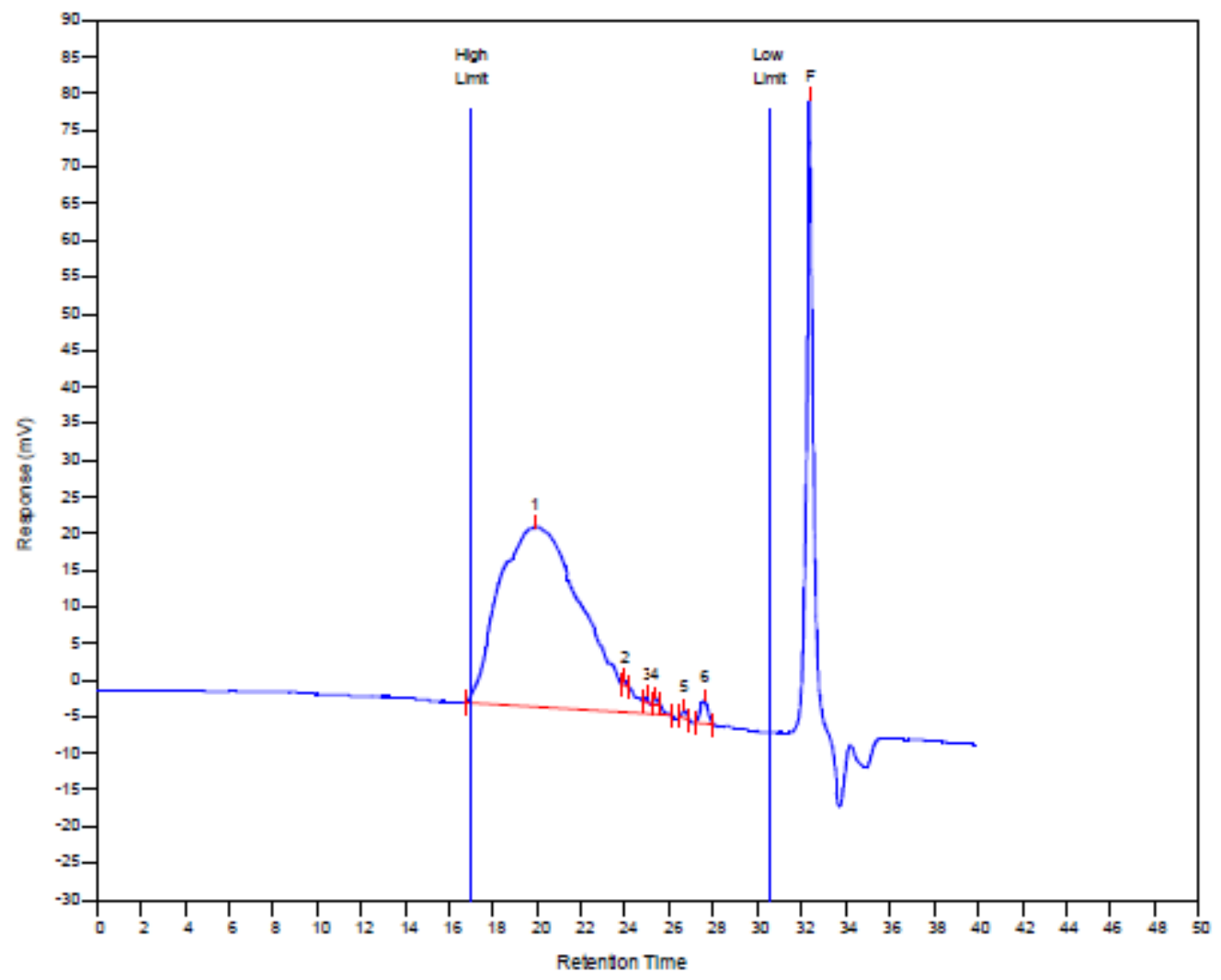

MW Averages

\begin{tabular}{rrrrrrrr} 
Peak No & \multicolumn{1}{c}{ Mp } & \multicolumn{1}{c}{ Mn } & \multicolumn{1}{c}{ Mw } & \multicolumn{1}{c}{ Mz } & Mz+1 & \multicolumn{1}{c}{ Mv } & \multicolumn{1}{c}{ PD } \\
1 & 24785 & 10873 & 38211 & 100440 & 169109 & 31954 & 3.5143 \\
2 & 2612 & 2651 & 2594 & 2624 & 2626 & 2581 & 0.978499 \\
3 & 1758 & 1763 & 1749 & 1758 & 1759 & 1745 & 0.992059 \\
4 & 1497 & 1498 & 1485 & 1494 & 1495 & 1482 & 0.991322 \\
5 & 885 & 893 & 887 & 892 & 893 & 886 & 0.993281 \\
6 & 612 & 624 & 626 & 629 & 631 & 625 & 1.00321
\end{tabular}




\section{YP42}

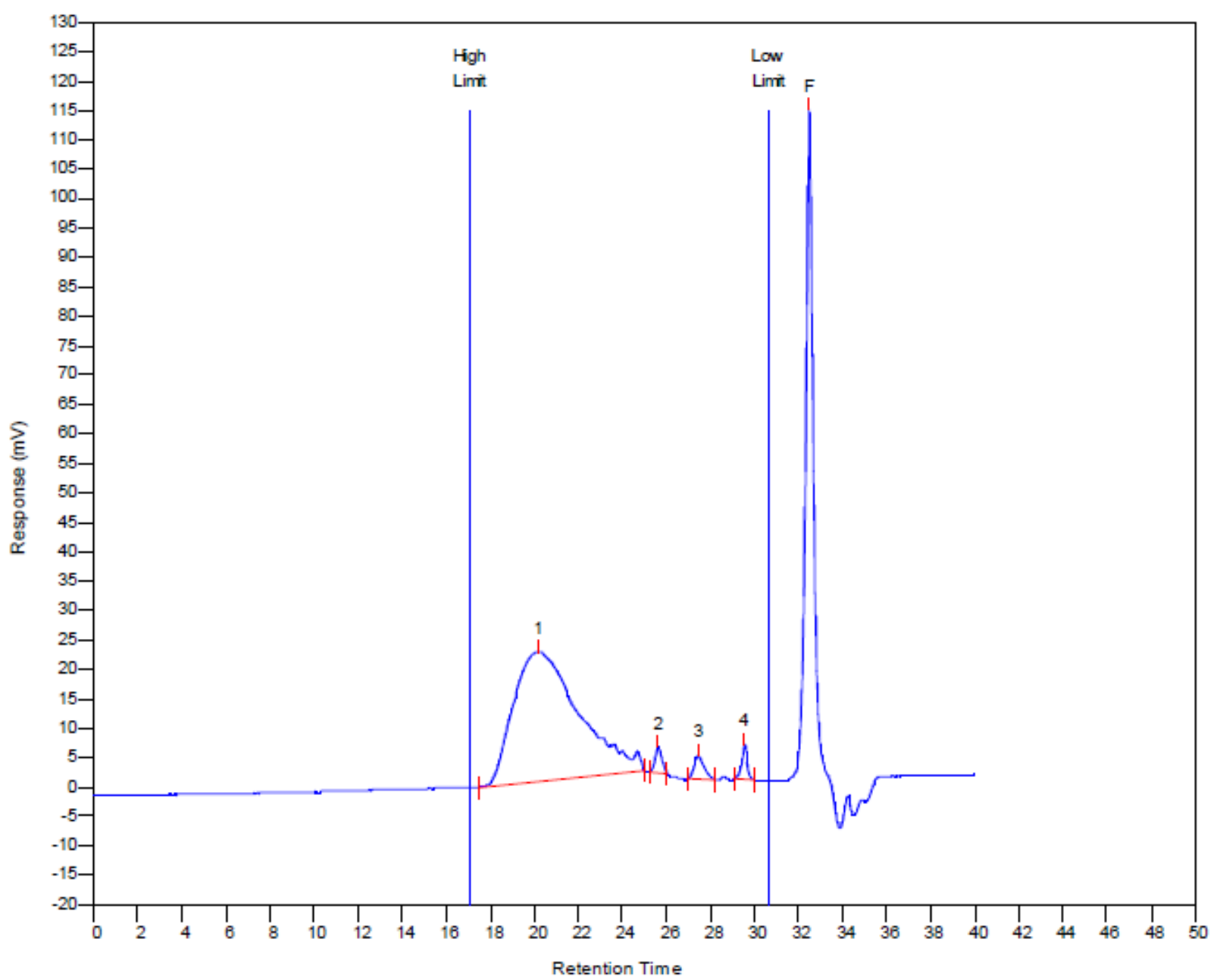

MW Averages

\begin{tabular}{rrrrrrrc} 
Peak No & \multicolumn{1}{c}{ Mp } & \multicolumn{1}{c}{ Mn } & \multicolumn{1}{c}{ Mw } & \multicolumn{1}{c}{ Mz } & $M z+1$ & \multicolumn{1}{c}{ Mv } & PD \\
1 & 24722 & 10420 & 24572 & 46495 & 70012 & 21925 & 2.35816 \\
2 & 1349 & 1345 & 1348 & 1353 & 1358 & 1347 & 1.00223 \\
3 & 656 & 646 & 651 & 656 & 661 & 650 & 1.00774 \\
4 & 268 & 268 & 269 & 270 & 271 & 268 & 1.00373
\end{tabular}




\section{YP43}

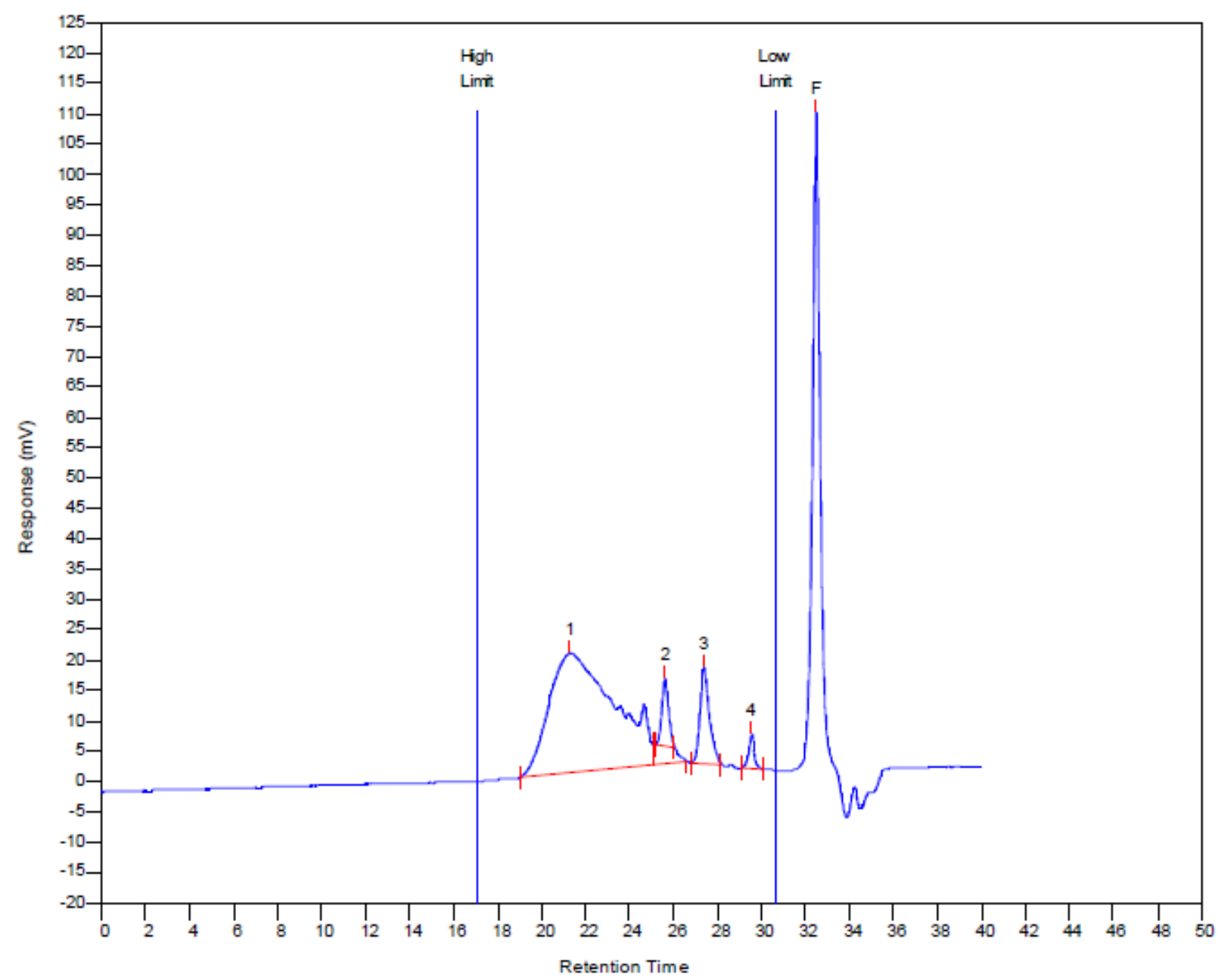

\section{MW Averages}

\begin{tabular}{rrrrrrrc} 
Peak No & \multicolumn{1}{c}{$M p$} & Mn & Mw & \multicolumn{1}{c}{$M z$} & $M z+1$ & $M v$ & $P D$ \\
1 & 11014 & 5546 & 9613 & 15345 & 21263 & 8875 & 1.73332 \\
2 & 1367 & 1354 & 1357 & 1362 & 1367 & 1356 & 1.00222 \\
3 & 674 & 661 & 666 & 671 & 676 & 665 & 1.00756 \\
4 & 268 & 267 & 268 & 269 & 271 & 268 & 1.00375
\end{tabular}




\section{YP44}

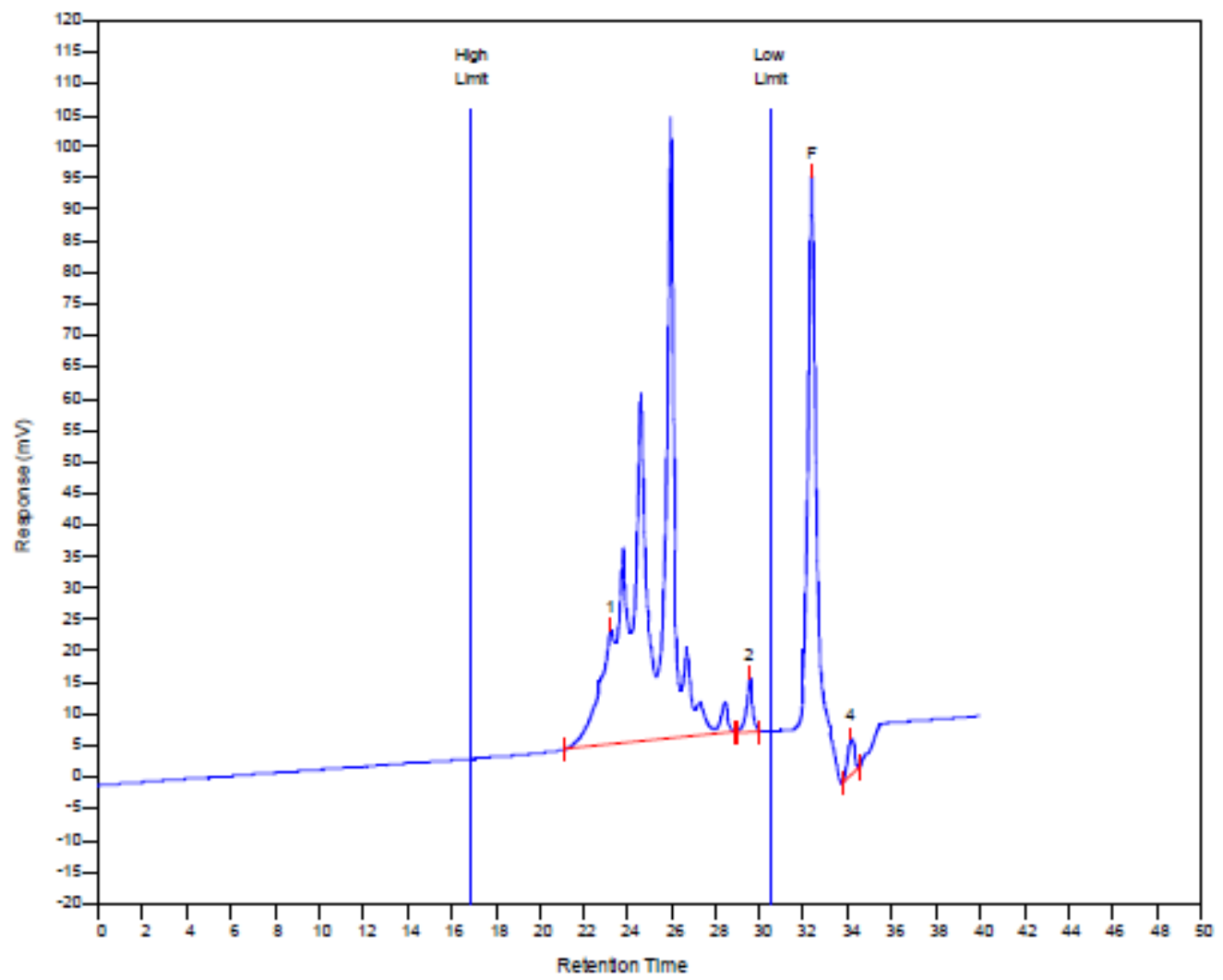

MW Averages

$\begin{array}{llllllll}\text { Peak No } & \mathrm{Mp} & \mathrm{Mn} & \mathrm{Mw} & \mathrm{Mz} & \mathrm{Mz}+1 & \mathrm{Mv} & \mathrm{PD}\end{array}$

$\begin{array}{llllllll}1 & 1163 & 1508 & 2033 & 2781 & 3704 & 1940 & 1.34814\end{array}$ 


\section{YP45}

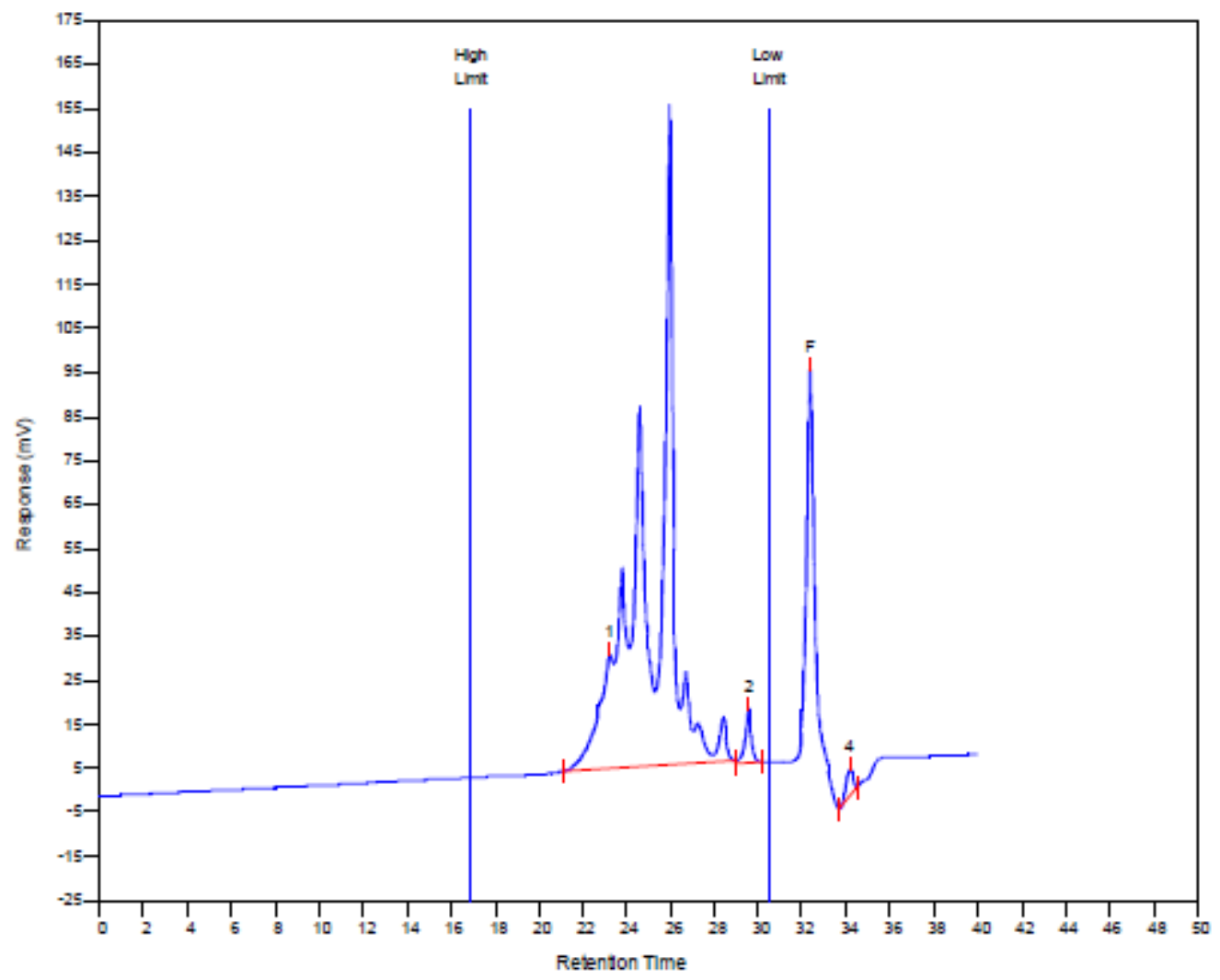

MW Averages

$\begin{array}{lllllllll}\text { Peak No } & \mathrm{Mp} & \mathrm{Mn} & \mathrm{Mw} & \mathrm{Mz} & \mathrm{Mz}+1 & \mathrm{Mv} & \mathrm{PD}\end{array}$

$\begin{array}{llllllll}1 & 1170 & 1470 & 1992 & 2738 & 3685 & 1899 & 1.3551\end{array}$

$\begin{array}{llllrrrr}2 & 252 & 254 & 255 & 257 & 259 & 254 & 1.00394\end{array}$ 
S9: DSC Thermograms

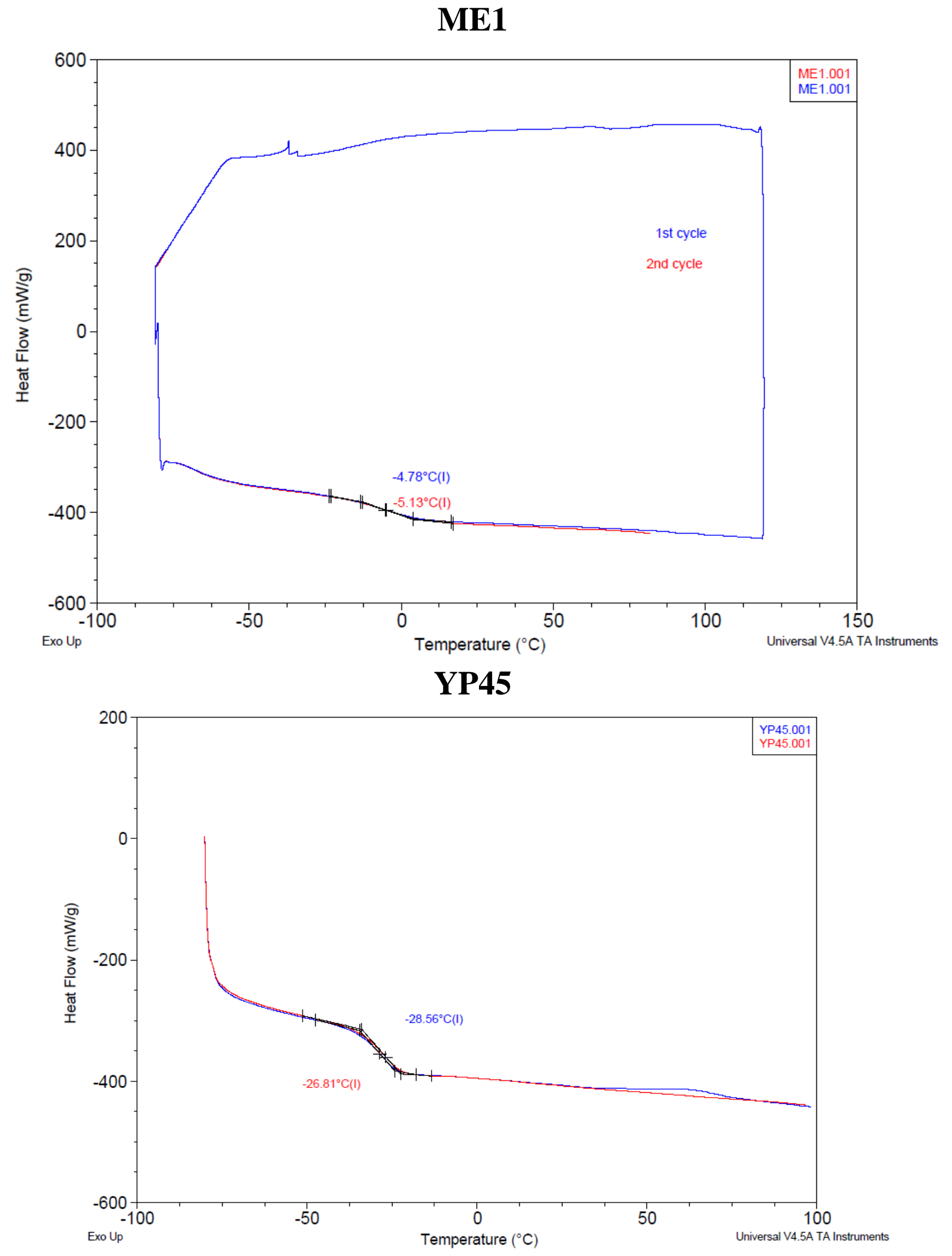

